\title{
COMPARISON OF IMMUNOLOGIC RESPONSES FOLLOWING INTRANASAL AND ORAL ADMINISTRATION OF A USDA-APPROVED, LIVE-ATTENUATED \\ STREPTOCOCCUS EQUI VACCINE
}

\author{
by
}

\section{KATHERINE DELPH}

B.S., Purdue University, 2007

D.V.M., Purdue University, 2012

\section{A THESIS}

submitted in partial fulfillment of the requirements for the degree

\section{MASTER OF SCIENCE}

Department of Clinical Science

College of Veterinary Medicine

\section{KANSAS STATE UNIVERSITY \\ Manhattan, Kansas}

2016

Approved by:

Major Professor

Elizabeth Davis, DVM, PhD, DACVIM-LAIM 


\section{Copyright}

KATHERINE DELPH

2016 


\begin{abstract}
Background: While there is a commercially-available vaccine for Streptococcus equi subsp. equi licensed for the intranasal route of administration, some equine practitioners are administering this vaccine orally despite a lack of evidence for its efficacy by this route of administration.

Objectives: To compare systemic and local immune responses following intranasal or oral administration of the USDA-approved, live-attenuated Streptococcus equi subspecies equi vaccine (Pinnacle IN®, Zoetis, Florham Park, New Jersey).

Study Design: Experimental, randomized clinical trial

Methods: Eight healthy horses with low Streptococcus equi M protein $(\mathrm{SeM})$ titers $(<1: 1600)$ were randomly assigned to an intranasal or oral two-vaccine series. SeM-specific serum immunoglobulins $\mathrm{G}(\mathrm{IgG})$ and $\mathrm{A}(\mathrm{IgA})$ and nasal secretion $\operatorname{Ig} \mathrm{A}$ were assessed using a commercially-available ELISA (Equine Diagnostic Solutions, LLC, Lexington, Kentucky) and a novel magnetic microsphere assay utilizing fluorescence. A general linear mixed models approach was used for statistical data analysis.

Results: As expected, intranasal vaccinates showed substantial increases in both serum SeMspecific IgG and IgA levels post-vaccination $(\mathrm{P}=0.0006$ and $\mathrm{P}=0.007$, respectively). Oral vaccinates showed an increase in serum SeM-specific IgG post-vaccination $(\mathrm{P}=0.0150)$, though only one-third the magnitude of intranasal vaccinates. Oral vaccinates showed no evidence of change in SeM-specific IgA post-vaccination $(\mathrm{P}=0.15)$.

Main Limitations: Changes in mucosal antibody responses were not identified in this study which may be related to small change in antibody response, timing of sample collection, or method of nasal secretion collection.
\end{abstract}


Conclusions: Results indicate that intranasal or oral vaccine administration resulted in increased serum SeM-specific IgG, though the magnitude of response differed between routes. 


\section{Table of Contents}

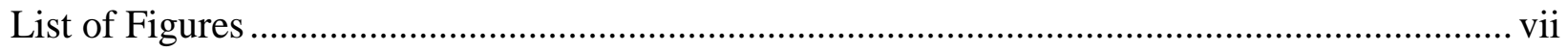

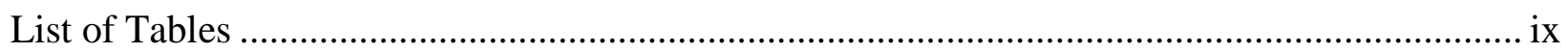

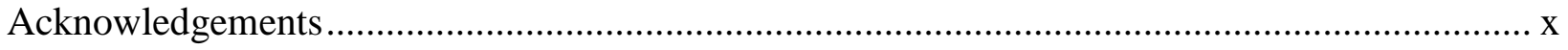

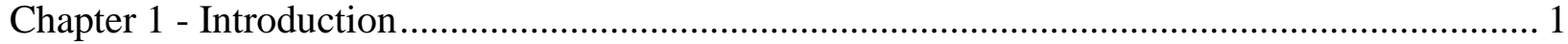

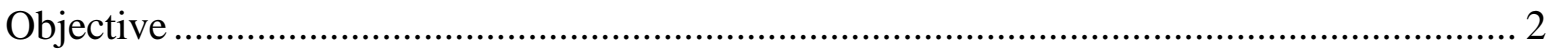

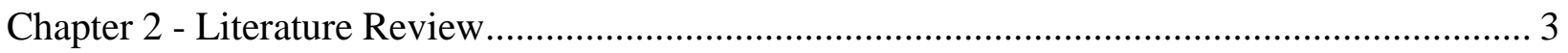

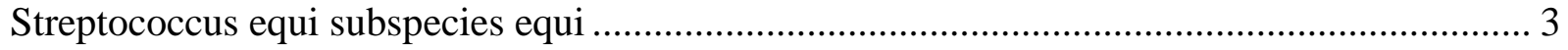



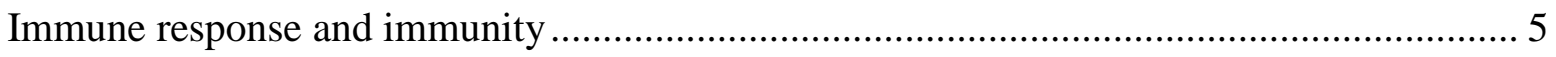

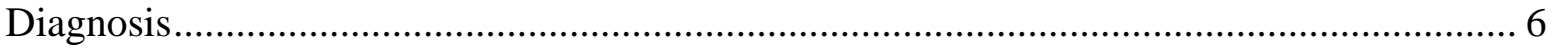

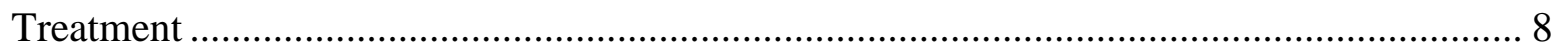

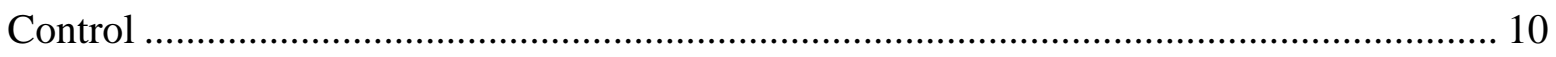

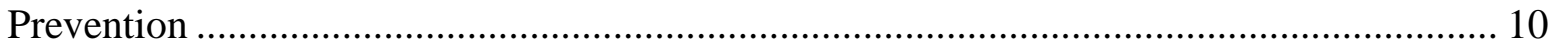

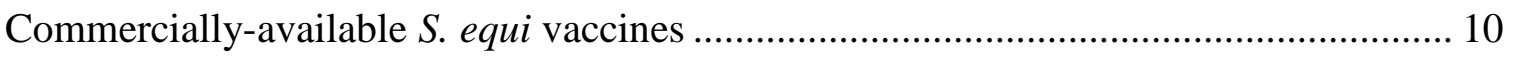

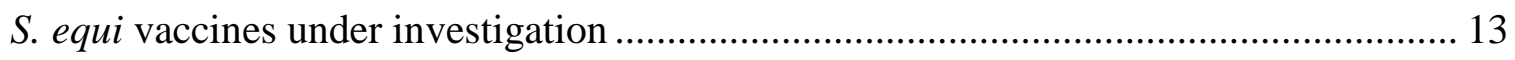

Stimulation of mucosal-associated lymphoid tissue .............................................. 17



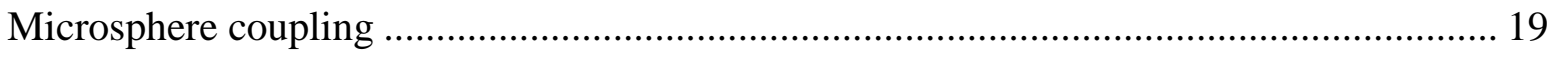

Advantages of microsphere immunoassays ........................................................... 19

Development of standard curves for quantitative measurements ................................... 20

Microsphere immunoassays utilized in equine veterinary medicine .............................. 22

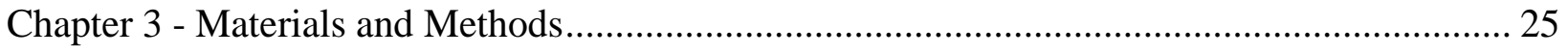

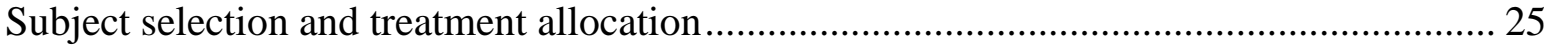

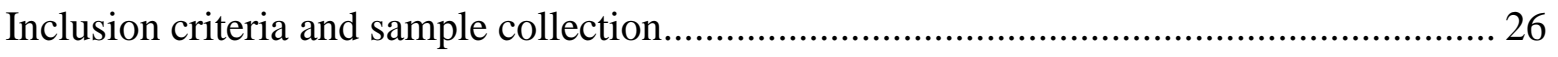

Protein coupling to magnetic microspheres ............................................................. 29

Quantitation (in MFI) of SeM protein-specific IgA I.................................................... 32

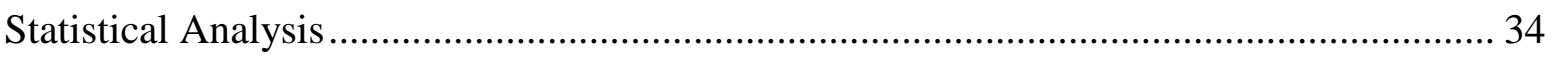

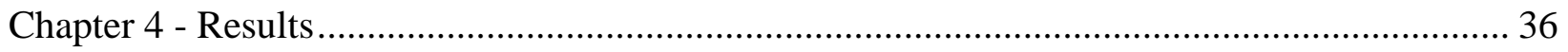




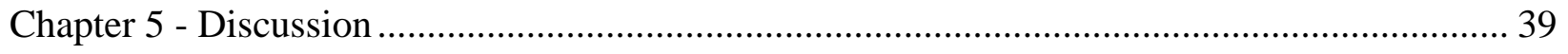

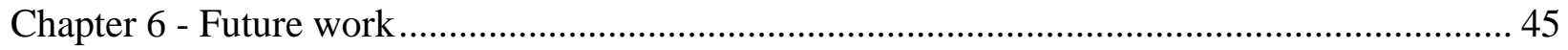

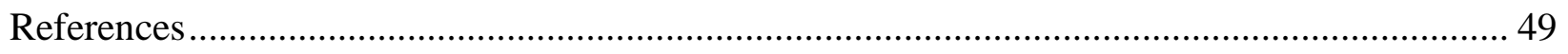




\section{List of Figures}

Figure 1: Standard curve generated using Milliplex® analyst software (EMD Millipore,

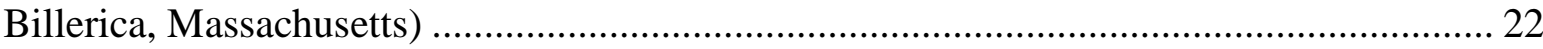

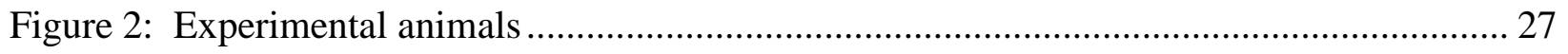

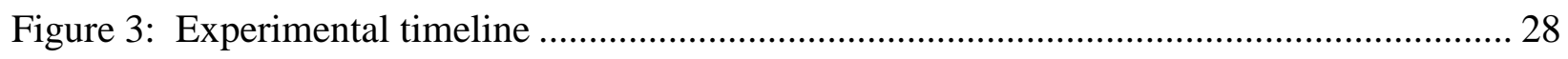

Figure 4: Microsphere labeling. Magnetic microspheres coated with SeM protein (A).

Experimental samples (B) incubated with microspheres. Analyte detection with a secondary goat anti-horse IgA antibody (C) and detection PE-conjugated donkey anti-goat

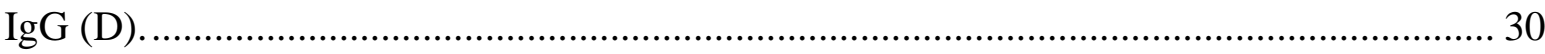

Figure 5: M protein coupling titration. Negative pre-vaccination serum sample and positive post-vaccination serum sample used for three different $M$ protein concentration $(2.5$ $\mu \mathrm{g} / 1 \times 10^{6}$ microspheres, $5 \mu \mathrm{g} / 1 \times 10^{6}$ microspheres, and $10 \mu \mathrm{g} / 1 \times 10^{6}$ microspheres). 30

Figure 6: BSA standard curve 32

Figure 7: Detection donkey anti-goat IgG antibody titrations of $1 \mu \mathrm{g} / \mathrm{ml}, 5 \mu \mathrm{g} / \mathrm{ml}$, or $10 \mu \mathrm{g} / \mathrm{ml}$ using an IgG standard curve.

Figure 8: Least square mean estimates (and corresponding 95\% confidence intervals) of serum IgG SeM titer (Equine Diagnostic Solutions, LLC, Lexington, Kentucky) at baseline prior to vaccination (week 0 ) and 4 weeks following a 2-dose vaccine series (week 7) for horses vaccinated via intranasal (purple diamond symbols) or oral (red cross symbols) routes. Arrows indicate time of vaccine administration. ${ }^{\mathrm{x}, \mathrm{y}}$ Different letters indicate differences $(\mathrm{P}<0.05)$ from baseline to 7 weeks into the study (i.e. 4 weeks post-booster) within each vaccination group. ${ }^{\mathrm{a}, \mathrm{b}}$ Different letters indicated difference $(\mathrm{P}<0.05)$ between intranasal and oral vaccinates at 7 weeks into the study. Point estimates were jittered horizontally to allow for clear visualization.

Figure 9: Least square mean estimates (and corresponding 95\% confidence intervals) of serum SeM-specific IgA (in MFI) at baseline prior to vaccination (week 0) and 2 weeks following a 2-dose vaccine series (week 5) for horses vaccinated via the intranasal (purple diamond symbols) or oral (red cross symbols) routes. Arrows indicate time of vaccine administration. ${ }^{\text {a,b }}$ Different letters indicated difference $(\mathrm{P}<0.05)$ between intranasal and 
oral vaccinates at 5 weeks into the study. Point estimates were jittered horizontally to allow for clear visualization. 37

Figure 10: : Least square mean estimates (and corresponding 95\% confidence intervals) of nasal secretion SeM-specific IgA (in MFI) at baseline prior to vaccination (week 0) and 2 weeks following a 2-dose vaccine series (week 5) for horses vaccinated via the intranasal (purple diamond symbols) or oral (red cross symbols) routes. Arrows indicate time of vaccine administration. Point estimates were jittered horizontally to allow for clear visualization. 38

Figure 11: Least square mean estimates (and corresponding 95\% confidence intervals) of serum IgG SeM titer (Equine Diagnostic Solutions, LLC, Lexington, Kentucky) at baseline prior to vaccination (week 0) and 4 weeks following a 2-dose vaccine series (week 7) for horses vaccinated with intranasal saline. Arrows indicate time of vaccine administration. Intranasal saline vaccination was performed at a separate time point than experimental animal vaccinations; therefore, direct comparison between this group and experimental animals could not be performed.

Figure 12: Least square mean estimates (and corresponding 95\% confidence intervals) of serum SeM-specific IgA (in MFI) at baseline prior to vaccination (week 0) and 2 weeks following a 2-dose vaccine series (week 5) for horses vaccinated with intranasal saline. Arrows indicate time of vaccine administration. Intranasal saline vaccination was performed at a separate time point than experimental animal vaccinations; therefore, direct comparison between this group and experimental animals could not be performed.

Figure 13: Least square mean estimates (and corresponding 95\% confidence intervals) of nasal secretion SeM-specific IgA (in MFI) at baseline prior to vaccination (week 0) and 2 weeks following a 2-dose vaccine series (week 5) for horses vaccinated with intranasal saline. Arrows indicate time of vaccine administration. Intranasal saline vaccination was performed at a separate time point than experimental animal vaccinations; therefore, direct comparison between this group and experimental animals could not be performed.

Figure 14: Standard curve generated using Milliplex ${ }^{\circledR}$ analyst software (EMD Millipore, Billerica, Massachusetts) 


\section{List of Tables}

Table 1: SeM ELISA titer interpretation (Sweeney et al. 2005) ............................................. 7

Table 2: Data from serum with known IgG concentrations (ng/ml) used to generate a standard curve using Milliplex ${ }^{\circledR}$ analyst software (EMD Millipore, Billerica, Massachusetts)....... 21

Table 3: Data from serum with known IgA concentration $(\mathrm{ng} / \mathrm{ml})$ used to generate a standard curve using Milliplex ${ }^{\circledR}$ analyst software (EMD Millipore, Billerica, Massachusetts). ....... 46 


\section{Acknowledgements}

I would like to express my appreciation to my major professor, Dr. Beth Davis, for her continual support and guidance throughout this project, my graduate school experience, and my residency program at Kansas State University. I would like to thank my committee members, Dr. Melinda Wilkerson and Dr. Susan Moore, for their support of this project and my graduate school experience. I would like to thank my fellow authors on the manuscript, entitled "Comparison of immunologic responses following intranasal and oral administration of a USDA-approved, liveattenuated Streptococcus equi vaccine" that is currently under review, including Dr. Beth Davis, Dr. Nora Bello, Dr. Keith Hankins, Dr. Melinda Wilkerson, and Dr Catherine Ewen. Dr. Melinda Wilkerson, Dr. Catherine Ewen, and Anushka George were instrumental in helping me learn how to perform the assays in the lab. I would also like to thank Dr. John Timoney, Gluck Equine Research Center, University of Kentucky, Lexington, Kentucky for provision of S. equi M protein; Dr. Jennifer Morrow, Equine Diagnostic Solution, LLC, Lexington, Kentucky for performing SeM protein titer assays; and Kara Smith for technical assistance. I would like to thank Zoetis, Inc for funding for this project. Without many people's support and guidance, this project would not have been possible. 


\section{Chapter 1 - Introduction}

Streptococcus equi subspecies equi, a gram-positive, Lancefield group C streptococci, is a highly contagious upper respiratory tract bacterial pathogen of horses. In susceptible populations, morbidity to S. equi can reach $100 \%$ (Ainsworth and Cheetham. 2010). Due to its high contagiousness and its short and long-term equine health implications, control of Streptococcus equi is of paramount importance to the equine industry. Infection with $S$. equi begins with entry into the mouth or nose, where the bacteria attaches to lingual, palatine, pharyngeal, and tubal tonsils (Sweeney et al. 2005). Virulence factors including exposed surface proteins are involved in the attachment and penetration to tonsils, followed by translocation to submandibular and retropharyngeal lymph nodes, and finally prevention of bacterial phagocytosis and destruction by neutrophils (Sweeney et al. 2005; Timoney and Kumar. 2008).

After recovery, approximately $75 \%$ of horses develop a strong, enduring immunity that persists for 5 years or more (Sweeney et al. 2005). Optimal immunity likely relies on both systemic and mucosal immune responses (Timoney. 2004); therefore, efficacious vaccines likely need to stimulate both for protection. A non-encapsulated, live-attenuated strain of $S$. equi (Pinnacle IN®, Zoetis, Florham Park, New Jersey) has demonstrated efficacy against experimental challenge (Walker and Timoney. 2002). The intranasal administration of this attenuated vaccine mimics natural exposure to the pathogen and thus intends to stimulate a similar immune response. Adverse effects have been associated with this vaccine including abscess formation at remote sites, development of disease, or purpura hemorrhagica (Borst et al. 2011). Another common problem associated with intranasal vaccination is removal of the attenuated strain by sneeze-mediated expulsion of nasal secretions. Due to these challenges, the zoonotic potential of S. equi (Breiman and Silverblatt. 1986), and difficulty with the intranasal route of administration, some equine 
practitioners have adopted the oral route of vaccine administration for their equine patients. However, to date there is no evidence to support that oral vaccination elicits a systemic immune response that could potentially confer host protection to pathogen challenge.

\section{Objective}

Therefore, the primary objective of this study was to compare immune responses following oral administration of the attenuated vaccine strain relative to that of the licensed intranasal route of vaccination. We hypothesized that the attenuated vaccine strain would come in contact with the pharyngeal tonsils following oral administration, as occurs with natural infection, thereby eliciting a measurable immune response. We monitored the systemic immune response by means of serum S. equi $\mathrm{M}$ protein (SeM) specific immunoglobulins $\mathrm{G}(\mathrm{IgG})$ and $\mathrm{A}$ (IgA), and the mucosal immune response using nasal secretion SeM-specific IgA. Based on results, recommendations for the alternative route of vaccine administration can be made. 


\section{Chapter 2 - Literature Review}

\section{Streptococcus equi subspecies equi}

Streptococcus equi subspecies equi is a gram-positive, $\beta$-hemolytic, Lancefield group C streptococci. It is a highly contagious upper respiratory tract bacterial pathogen and the causative agent of one of the most common infectious diseases of horses, known as strangles. In susceptible populations, morbidity to S. equi can reach 100\% (Ainsworth and Cheetham. 2010). Clinical signs include fever, pharyngitis, and rhinitis, followed by lymphadenopathy, subsequent abscess formation, and rupture of the retropharyngeal and submandibular lymph nodes. As lymph nodes rupture, mucopurulent nasal discharge from the retropharyngeal lymph nodes which rupture into the guttural pouches or purulent drainage from the submandibular lymph nodes typically develops. Lymphadenopathy may cause compression of the pharynx, larynx, or trachea causing significant dyspnea requiring intervention until lymph node abscess maturation and rupture. This situation gives the infection its common name of "strangles." Predictor variables associated with development of strangles include mucopurulent nasal discharge, external abscessation, and season where strangles is more common in the spring than summer (Duffee et al. 2015).

Some horses that are affected with strangles remain persistently infected in their guttural pouches after rupture of the retropharyngeal lymph nodes and are asymptomatic, chronic carriers that serve as a potential source of outbreaks. With chronicity, guttural pouch empyema becomes inspissated forming chondroids which harbor the organism. Prevalence of the development of carriers associated with strangles outbreaks reportedly ranges from $0.3 \%$ to $10 \%$ (Sweeney et al. 1987; Newton et al. 1997; Waller and Jolley. 2007). Another study that defined asymptomatic 
carriers as being positive on nasopharyngeal wash PCR 40 days after infection reported a prevalence of 30\% (Duffee et al. 2015).

Less common manifestations of infection include disseminated metastatic abscesses, immune-mediated purpura hemorrhagica, or myositis. Disseminated abscesses develop via hematogenous or lymphatic routes. Abscesses can develop in remote lymph nodes, organs such as lungs, liver, kidneys, spleen, and rarely brain, heart, and joints. Prevalence of metastatic abscessation development associated with strangles outbreaks range from 1.9\% (Duffee et al. 2015) and 2.7\% (Sweeney et al. 1987) up to 20\% (Whelchel and Chaffin. 2009). Immunemediated purpura hemorrhagica is a type III immune complex hypersensitivity reaction that typically occurs 3-4 weeks after strangles infection or vaccine administration. Immune complexes deposit within blood vessels to cause a vasculitis. Clinical signs include ventral and peripheral edema, skin necrosis and sloughing, and mucosal petechial and ecchymotic hemorrhages. Prevalence of purpura hemorrhagica following strangles outbreak is reported to range from 2\% (Sweeney et al. 1987) to 6.5\% (Duffee et al. 2015). Risk factors associated with purpura hemorrhagica development include pre-existing high SeM titers (>1:1600) and anemia (Duffee et al. 2015). Rarely infarction of various organs including the gastrointestinal tract, muscles, and lungs occurs associated with purpura hemorrhagica. Infarctive purpura hemorrhagica has a high fatality rate and is associated with clinical signs of muscle stiffness, colic, and severe pain and recumbency. Immune-mediated myositis may also develop secondary to strangles infection due to cross reaction of myosin and S. equi M protein. Typically middleaged Quarter horses are affected, and clinical signs include depression and rapid, severe muscle atrophy. 


\section{Pathogenesis}

Infection with $S$. equi begins with entry into the mouth or nose, where the bacteria attaches to lingual, palatine, pharyngeal, and tubal tonsils (Timoney and Kumar. 2008). Virulence factors including exposed surface proteins (SzPSe, Se73.9, and Se51.9) are involved in attachment and penetration to tonsils (Sweeney et al. 2005). The organism then translocates to the submandibular and retropharyngeal lymph nodes that drain the tonsils. Chemotactic factors attract neutrophils to the infected lymph nodes; however, other virulence factors (combination of hyaluronic acid capsule, antiphagocytic SeM protein, and Mac protein) prevent bacterial phagocytosis and destruction by neutrophils (Harrington et al. 2002; Timoney and Kumar. 2008; Timoney et al. 2014). Attraction of neutrophils and prevention of destruction leads to abscess formation; rupture of abscesses leads to dissemination. Fever occurs 3-14 days following exposure and nasal shedding begins 2-3 days after onset of fever. Elimination of nasal shedding of the organism after 2-3 weeks coincides with the development of systemic and mucosal immune responses (Galan and Timoney. 1985). Monocytes and tonsillar macrophages play a major role in $S$. equi clearance as they have bactericidal activity in the presence of convalescent antibody through organism interiorization and phagocytosis (Merant et al. 2011). Pre-existing humoral and cellular immunity help protect against clinical disease development after exposure (Nara et al. 1983).

\section{Immune response and immunity}

After recovery, $75 \%$ of horses develop a strong, enduring immunity that persists for 5 years or more (Sweeney et al. 2005). SeM is highly immunogenic. Various projects have studied the immune response following experimental $S$. equi infection. Horse $\operatorname{IgG}$ subisotypes include $\operatorname{IgGa}$, IgGb, IgGc, and $\operatorname{IgG}(\mathrm{T})$ (Sheoran et al. 1997), where IgGb is the most important subisotype with regard to protective immunity (Sheoran et al. 2000). Horse $\operatorname{Ig} \mathrm{A}$ is present as serum or secretory 
$\operatorname{IgA}$, where serum $\operatorname{IgA}$ is typically a dimer (Sheoran et al. 1997). SeM-specific serum $\operatorname{IgGa}$ is produced shortly after infection, SeM-specific mucosal IgA and IgGb are produced during acute and convalescent periods (Sheoran et al. 1997), and SeM-specific serum IgGb as well as serum IgGb to surface exposed proteins are produced late in convalescence in some horses (Timoney and Eggers. 1985). Serum SeM-specific IgGb is predominant during both the acute and convalescent periods from weeks 3 to 28 after infection (Sheoran et al. 1997). Serum SeM-specific IgGa is present from week 2 to 14 after infection (Sheoran et al. 1997). Serum SeM-specific IgA is present late in infection from weeks 5 to 14 after infection (Sheoran et al. 1997). Mucosal $\operatorname{IgA}$ and $\operatorname{IgG}$ are detected 1-2 weeks after infection but are much higher at 6-7 weeks after infection (Galan and Timoney. 1985). Mucosal IgA was detected from weeks 3 to 28 after experimental infection where nasopharyngeal washes were used to collect mucosal samples (Sheoran et al. 1997). SeM-specific $\operatorname{IgGa}, \operatorname{IgGb}$, and $\operatorname{IgA}$ were found to have opsonophagocytic activity in the presence of complement (Sheoran et al. 1997). The mucosal antibodies that are produced protect against further infection by either preventing adhesion of the bacterium or preventing interiorization to tonsillar cells (Galan and Timoney. 1985; Timoney. 2004). Optimal immunity likely relies on both systemic and mucosal immune responses (Timoney. 2004); therefore, efficacious vaccines likely need to stimulate both for protection.

\section{Diagnosis}

Diagnosis of classic strangles relies on culture or polymerase chain reaction (PCR) of ideally purulent material. Other samples that can be tested include nasopharyngeal lavage, guttural pouch lavage, or less ideally nasopharyngeal or nasal passage swab. Nasopharyngeal wash PCR was found to have the highest detection rate (84\%) when compared to nasal passage swab culture (37\%) or PCR (53\%) or nasopharynx swab culture (37\%) or PCR (72\%) (Lindahl et 
al. 2013). In order for culture or PCR to be positive, the horse must be shedding the bacterium (24-48 hours after onset of fever). Culture will detect live organisms, while PCR, which is detecting the SeM protein, will not differentiate between live or dead organisms. Guttural pouch endoscopy can be performed to visual enlarged retropharyngeal lymph nodes.

Diagnosis of an asymptomatic carrier is through endoscopy to visualize guttural pouch empyema or chondroids followed by guttural pouch lavage culture or PCR for S. equi. If endoscopy is not available, nasopharyngeal lavage culture or PCR for S. equi is indicated.

To diagnose disease complications such as disseminated metastatic abscessation or purpura hemorrhagica, serology directed against SeM protein can be performed (Table 1). The SeM titer is most useful to determine need for vaccination or risk of purpura hemorrhagica and to diagnose metastatic abscessation or purpura hemorrhagica. Because at pre-existing high SeM titer is associated with development of purpura hemorrhagica following vaccination, studies have determined factors that are associated with horses having high titers (Boyle et al. 2009).

Increased age, Quarter horse and other breeds compared to Thoroughbreds and warmbloods, and previous vaccination increased the odds of having a SeM titer >/= 1:1600 (Boyle et al. 2009). None of the 21 horses with an SeM titer of 1:1600 or of the 5 horses with an SeM titer of 1:3200 at the time of revaccination developed any signs of purpura hemorrhagica (Boyle et al. 2009).

Table 1: SeM ELISA titer interpretation (Sweeney et al. 2005)

\begin{tabular}{|l|l|}
\hline SeM titer & $\begin{array}{l}\text { Interpretation (adapted from Sweeney } \text { et al. } \\
2005)\end{array}$ \\
\hline Negative & $\begin{array}{l}\text { No previous exposure or recent }(<7 \text { days }) \\
\text { exposure or vaccination. }\end{array}$ \\
\hline
\end{tabular}




\begin{tabular}{|l|l|}
\hline $1: 200-1: 400$ (Weak positive) & $\begin{array}{l}\text { Recent or remote exposure or vaccination. } \\
\text { Recommend recheck in } 7-14 \text { days to } \\
\text { determine if recent exposure. }\end{array}$ \\
\hline $1: 800-1: 1600$ (Moderate positive) & $\begin{array}{l}2-3 \text { weeks after exposure or vaccination or } \\
\text { infection } 6 \text { months to 2 years previously. }\end{array}$ \\
\hline $1: 3200-1: 6400$ (High positive) & $\begin{array}{l}4-12 \text { weeks after exposure or vaccination. } \\
\text { Vaccination contraindicated if titer }>1: 1600 .\end{array}$ \\
\hline$>1: 12,800$ (Very high positive) & $\begin{array}{l}\text { Often associated with metastatic abscessation } \\
\text { or purpura hemorrhagica }\end{array}$ \\
\hline
\end{tabular}

Some researchers have called the SeM ELISA into question because an M protein in Streptococcus equi subsp zooepidemicus (SzM) shares 2/3 homology with SeM increasing the possibility of false positives with this test. Recently an indirect ELISA (iELISA) using 2 antigens (antigens A and C) was compared to the SeM iELISA. This combined antigen A and antigen $\mathrm{C}$ iELISA increased sensitivity and specificity from $89.8 \%$ and $77.0 \%$, respectively, to 93.3\% and 99.3\%, respectively (Robinson et al. 2013).

\section{Treatment}

Appropriate treatment depends on stage of disease. Horses in the early stage of infection displaying just pyrexia and depression but no lymph node abscessation can be treated with 3 days of antibiotic therapy. This may prevent development of abscessation, but these horses remain susceptible to reinfection as they do not produce protective immunity.

Horse with evidence of external lymphadenopathy should be treated with the aim of encouraging abscess maturation. Hot packing may help with abscess maturation, or surgical drainage may be required. Daily lavage of the opened abscess should be performed until drainage stops. Nonsteroidal anti-inflammatories may be administered to control fever, inflammation, and pain associated with abscessation. Antibiotics are contraindicated in simple 
cases of lymphadenopathy as it suppress the bacteria within the enlarged lymph nodes but abscessation continues when antibiotics are discontinued.

Horses with complications of external lymphadenopathy including dyspnea associated with upper airway obstruction, dysphagia, or dehydration should be treated with antibiotics typically penicillin and supportive care. In cases of dyspnea, tracheostomy may be required. In these complicated cases, antibiotics will help to decrease the size of abscesses and prevent secondary infections associated with these complications such as aspiration pneumonia. Other supportive care may include nonsteroidal anti-inflammatories, intravenous fluids, or enteral feeding through a nasogastric tube.

Asymptomatic, chronic carriers should be treated to eliminate the carrier state. This may be accomplished through guttural pouch lavage, endoscopy and the use of memory-helical polyp retrieval basket through the biopsy channel, instillation of gelatin/penicillin solution into the affected guttural pouches, and even surgical intervention along with systemic antibiotic therapy.

Horses with metastatic abscessation require long-term systemic antibiotic therapy and local treatment and drainage of abscesses if possible along with supportive care as needed. Horses with purpura hemorrhagica require corticosteroids to control the immune response associated with the disease. Antibiotics are also indicated as purpura can develop in association with active $S$. equi infection as well as the immunosuppressive effects of corticosteroids increase the risk of developing secondary infection. Supportive care should be instituted as well which may include nonsteroidal anti-inflammatories, intravenous fluids, and hydrotherapy and bandaging for peripheral edema. 


\section{Control}

During an outbreak, strict quarantine, hygiene, and biosecurity are required. Because pyrexia is typically the first clinical sign, rectal temperatures of all exposed horses should be monitored daily. If pyrexia is detected, that horse should be quarantined and possibly treated. Before re-introduction to the herd after disease, testing should be performed to ensure that the horse is cleared of infection. Nasopharyngeal lavage, guttural pouch lavage, or nasopharyngeal swab culture can be performed for detection of live $S$. equi. This should be performed weekly for 3 weeks before the horse is deemed negative (Sweeney et al. 2005). Endoscopy should be performed on any asymptomatic horses that culture positive for $S$. equi to detect carrier animals.

\section{Prevention}

Appropriate biosecurity is important for the prevention of this highly contagious disease. When introducing new additions, appropriate quarantine (approximately 3 weeks) should be instituted. Vaccinations are also available for prevention, but none are considered fully protective.

\section{Commercially-available $S$. equi vaccines}

A non-encapsulated, modified live vaccine (MLV) (Pinnacle IN@, Zoetis, Florham Park, New Jersey) that is administered intranasally is available in the United States. This vaccine strain is S. equi strain CF32 which was isolated from a horse with strangles in New York in 1981 that is attenuated via N-methyl-N-nitro-N-nitrosoguanidine (NTG) treatment. The strain is acapsular through the deletion of hyaluronate synthase (hasA and hasB) genes which produce the capsule (Walker and Timoney. 2002). This deletion prevents the vaccine strain from reverting to virulence, and it can be distinguishes from the wild-type strain which forms mucoid colonies because the vaccine strain forms small, dry colonies on culture (Walker and Timoney. 2002). 
The intranasal route of administration is meant to mimic natural exposure to elicit both local mucosal and systemic immune responses. Efficacy studies found significant differences in vaccinated and controls with regard to mortality (10-15\% and 60\%, respectively), disease incidence (ruptured lymph nodes), clinical score (nasal discharge, depression, fever, labored breathing, abscessed lymph nodes), and leukocytosis (Fort Dodge Animal Health licensing report TIA number: 22740. 1997). Complications of vaccination include development of purpura hemorrhagica, development of abscesses at remote sites, and possibly development of clinical disease with the vaccine strain. This vaccine does not appear to be safe for horse under 1 year of age because four 6 month-old ponies vaccinated with Pinnacle IN® (Zoetis, Florham Park, New Jersey) developed retropharyngeal abscessation due to the vaccine strain following vaccination compared to no clinical signs in ponies over 1 year of age that were similarly vaccinated (Borst et al. 2011). In this study, the vaccine strain was found to still be present in nasal swabs up to 36 days after vaccination and in tonsil swabs up to 46 days after vaccination which is potentially concerning because of the potential for reversion to virulence (Borst et al. 2011). Cursons et al. (2015) reported on a yearling filly and a 10 month-old filly that developed submandibular lymph node abscesses following vaccination with Pinnacle IN@ (Zoetis, Florham Park, New Jersey). The infecting strains were found to be similar to the vaccine strain through genome sequencing (Cursons et al. 2015).

A bacterial extract vaccine containing purified $\mathrm{M}$ protein antigen with aluminum adjuvant (Strepvax II, Boehringer Ingelheim Vetmedica, Inc, St. Joseph, Missouri) that is administered intramuscularly is also available in the United States. This vaccine reportedly reduces amount and severity of clinical disease (Mallicote. 2015). Complications include development of purpura hemorrhagica and development of abscesses at the site of injection (Hoffman et al. 1991). 
A MLV (Equilis® StrepE, MSD Animal Health, Kempton Park, South Africa) that is administered by mucosal injection in the upper lip is available in Europe. This strain is attenuated by the deletion of the aroA gene which affects aromatic amino acid synthesis (Kelly et al. 2006). In efficacy studies, $75 \%$ protection was afforded in challenge studies (Equilis ® StrepE Data Sheet 2014, MSD Animal Health, www.msd-animal-health.co.uk). Complications of this vaccine also include development of purpura hemorrhagica, development of abscesses at remote injection sites, and development of clinical disease associated with the vaccine strain. Jacobs et al. (2000) reported efficacy against challenge in five 9-11 month-old foals and minimal side effects of mild swelling at the injection site for 2 weeks after vaccination. Kemp-Symonds et al. (2007) reported the first 2 cases of vaccine strain-induced abscessation. A 7 year-old horse developed a cervical musculature abscess at the site of another injection following vaccination, and a 5 year-old pony developed submandibular lymphadenopathy consistent with strangles following vaccination (Kemp-Symonds et al. 2007). The infecting strain was confirmed to be the vaccine strain through PCR and gene sequencing (Kemp-Symonds et al. 2007).

When comparing experimental infection with $S$. equi to intramuscular extract vaccination (Strepguard®, Intervet/Merck Animal Health, Summit, New Jersey), the serum antibody response to cell surface antigens differed (Velineni et al. 2015). Another study compared experimental convalescent horses with intramuscularly vaccinated horses (Strepguard®, Intervet/Merck Animal Health, Summit, New Jersey) (Sheoran et al. 1997). Serum SeM-specific IgGb and IgGa were detected 1 week after vaccination and the peak increase of both were significantly higher than convalescent horses. However, mucosal IgG or IgA were not detected in nasopharyngeal washes of vaccinated horses (Sheoran et al. 1997). 
One study compared the serum antibody response following vaccination with either the intramuscular extract vaccine (Strepguard®, Intervet/Merck Animal Health, Summit, New Jersey) or the intranasal modified-live vaccine (MLV) (Pinnacle IN®, Zoetis, Florham Park, New Jersey) and then experimental challenge (Hobo et al. 2010). A serologic response to proline-glutamic acid-proline-lysine antigen with five repetitions (PEPK-5R) was tested. The extract vaccine elicited a slightly higher immune response than the MLV, and after challenge, the immune response to PEPK-5R was significantly higher in the extract vaccine group compared to the MLV group (Hobo et al. 2010). One out of three horses in the extract vaccine group and two out of three horses in the MLV group developed lymphadenopathy with rupture where the challenge strain of S. equi was identified via PCR (Hobo et al. 2010).

\section{S. equi vaccines under investigation}

Many researchers have investigated other antigens, adjuvants, or delivery methods for $S$. equi vaccination as none of the commercially-available vaccines are fully protective. An ideal vaccine would be $100 \%$ protective, easily administered (intramuscularly for horses), have no adverse effects, and be able to be differentiated from infection. None of the commerciallyavailable vaccines fulfill these ideal requirements.

Flock et al. (2004) used S. equi extracellular antigens including two fibrinogen binding proteins (FNZ and SFS) and an IgG, serum albumin, and $\alpha_{2}$ macroglobulin-binding surface protein (EAG) with or without adjuvant (E. coli heat-labile enterotoxin B) as a vaccination. These antigens with or without adjuvant were administered intranasally, subcutaneously, or both. Only horses receiving the antigens with adjuvant by both the intranasal and subcutaneous routes exhibited high mucosal antigen-specific $\operatorname{IgA}$, while horses that received the three antigens with adjuvant by either the intranasal route alone or both intranasal and subcutaneous routes had 
elevated serum antigen-specific IgG (Flock et al. 2004). No adverse effects to this vaccine were noted, but challenge was not performed to determine the protective nature of the immune response elicited.

Recombinant S. equi proteins were used as intranasal antigens in mice to determine the immune response (Flock et al. 2006). Collagen-binding protein (CNE) and collagen-like protein (ScIC) vaccinations elicited protective antibodies after experimental infection (Flock et al. 2006). Fibrinonectin-binding protein (FNEB) did not elicit protective antibodies after experimental infection (Flock et al. 2006). A synergistic response was found with coadministration of CNE and EAG to elicit protective antibodies (Flock et al. 2006). These antigens were chosen to test in mice based on immune response to these antigens in serum from previously infected horses (Flock et al. 2006).

Waller et al. (2007) investigated these recombinant protein (EAG, CNE, and ScIC) as vaccine antigens in horses against experimental challenge. Nine 6 month-old ponies were vaccinated both intramuscularly and intranasally and seven 6 month-old ponies were used as unvaccinated control. Vaccination elicited serum and mucosal $\operatorname{IgG}$ responses but low mucosal IgA (Waller et al. 2007). After challenge, both vaccinated and control ponies displayed signs of clinical disease but disease severity was significantly reduced in vaccinated ponies (Waller et al. 2007).

Another group of surface proteins was investigated in horses exposed to S. equi infected horses to determine the immune response and protective capability (Timoney et al. 2007). One vaccine contained the antigens SzPSe, Se73.9, Se51.9, Se44.2, and Se46.8 and the other contained the antigens SeM, Se44.2, Se75.3, Se42.0, Se110.0, and Se18.9. Antibody responses were found to all proteins except Se51.9 and CNE, and antibodies specific to SeM and SzPSe 
were higher than other antibodies and persisted through 200 days after vaccination (Timoney et al. 2007). These antibody responses however did not afford protection against exposure to $S$. equi-infected horses (Timoney et al. 2007).

An intramuscular multigene deletion strain, where sagA, has $A$, seM, aroB, pyrC, and recA genes were deleted, was investigated (Robinson et al. 2015). Deletion of sagA, hasA, and seM genes was performed to reduce ability to resist phagocytosis and improve vaccine safety. Deletion of $\operatorname{sag} A$ caused loss of production of the hemolytic toxin, streptolysin S (SLS) making the colonies non-hemolytic as well as making the colonies less able to colonize tracheal mucosa (Robinson et al. 2015). Deletion of hasA resulted in non-encapsulated colonies susceptible to phagocytosis. Deletion of $\operatorname{aroB}$ and pyrC reduced the ability to produce aromatic amino acids and pyrimidines; and deletion of $r e c A$ reduced the environmental persistence by increasing the susceptibility to ultraviolet light (Robinson et al. 2015). Nine ponies were vaccinated intramuscularly on Day 0 and seven ponies were revaccinated on Day 56. Nine ponies were unvaccinated controls. All ponies were challenged on Day 52 after the second vaccine. Five of the nine vaccinated ponies developed injection site abscesses caused by the vaccine strain where two were removed from the study. Six out of nine control ponies were pyrexic following challenge whereas none of the seven vaccinated ponies were significantly febrile (Robinson et al. 2015). Nine out of nine control ponies had lymph node abscesses, whereas only one of the seven vaccinated ponies had a lymph node abscess (Robinson et al. 2015).

Cholera toxin (CT) as an adjuvant for intranasal administration of the immunogenic peptide (SeMF3) was evaluated in ponies in a challenge model (Sheoran et al. 2002). Cholera toxin is immunogenic and enhances uptake by mucosal-associated lymphoid tissue (MALT) (Sheoran et al. 2002). Ponies vaccinated with CT-SeMF3 developed higher serum SeMF3- 
specific IgGb and nasal SeMF3-specific IgA than control horses; however, when exposed to experimentally infected horses, vaccination did not confer protection (Sheoran et al. 2002).

A sucrose acetate isobutyrate (SAIB)-based delivery system for intranasal aerosol administration of an immunogenic peptide (SeMF3) was evaluated (Nally et al. 2001). Eleven horses were vaccinated with the SeMF3 with SAIB, and seven horses were vaccinated with just SeMF3 without SAIB at day 0 and week 4. Horses vaccinated with SeMF3 with SAIB had significantly elevated mucosal $\operatorname{IgA}, \operatorname{IgGa}$, and $\operatorname{IgGb}$ as well as serum $\operatorname{Ig} \mathrm{A}$ and $\operatorname{IgGb}$ compared to horses just vaccinated with SeMF3 without SAIB (Nally et al. 2001).

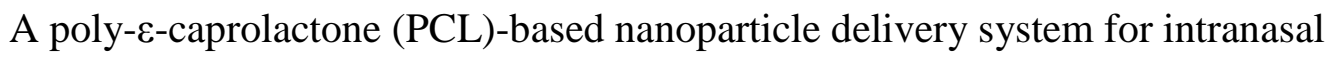
administration was evaluated in mice (Florindo et al. 2009). The PCL nanoparticles are biodegradable, increase the concentration of antigen to promote its interaction with antigen presenting cells, and protect antigens from proteolytic enzymes so they are useful as a vaccine delivery system especially to the MALT (Florindo et al. 2009). The nanoparticles used were coupled with either mucoadhesive polymers (alginate or chitosan) or adsorption enhancers (spermine or oleic acid) to act as carriers for S. equi surface proteins. Mice vaccinated with PCL nanoparticles with especially mucoadhesive polymers had more robust systemic IgG and mucosal IgA than mice vaccinated with free antigen only (Florindo et al. 2009). PCL nanoparticles are a potential delivery system for intranasal vaccinations.

Two positively charged delivery systems, liposomes and chitosan nanoparticles, with $S$. equi extracts for intranasal administration were evaluated in mice (Figueiredo et al. 2012). Systemic IgG with both Th1- and Th2-mediated immune responses were elicited by both delivery systems; while only the chitosan nanoparticle delivery system elicited mucosal IgA response (Figueiredo et al. 2012). 


\section{Stimulation of mucosal-associated lymphoid tissue}

Many practitioners are adopting the oral route of administration for the MLV (Pinnacle $\mathrm{IN}{ }^{\circledR}$, Zoetis, Florham Park, New Jersey) despite approval only for the intranasal route of administration. Intranasal administration can be difficult (Grogan and McDonnell. 2005) and may result in expulsion of the vaccine strain. The oral route of immunization is intriguing to stimulate mucosal-associated lymphoid tissue (MALT). The MALT of the upper respiratory tract blocks attachment and penetration of microbial pathogen through antibody and cellular responses. Nonspecific cellular immunity of the MALT includes complement, enzymes, and neutrophils and macrophages (Jakobsen and Jonsdottir. 2003). Membranous microvillus (M) cells overlie lymphoid tissue of inductive sites such as the tonsils in the pharynx and Peyer's patches of the jejunum and ileum (Kumar et al. 2001). M cells are intimately associated with antigen-presenting cells including dendritic cells, lymphocytes, and macrophages so that antigens can be rapidly transported to the underlying lymphoid tissue (Holmgren and Czerkinsky. 2005). Activation of M cells in the MALT causes homing of B cells to mucosal sites and production of specific IgA as well as systemic antibody production (Kumar et al. 2001). Secretory IgA is the predominant antibody involve in mucosal immunity, but IgM and IgG also contribute (Holmgren and Czerkinsky. 2005). Nasal- and bronchial-associated lymphoid tissue may be stimulated by gut-associated lymphoid tissue antigen presentation as they are all part of MALT (Wilkie. 1982). Oral administration of the non-encapsulated, live-attenuated S. equi vaccine (Pinnacle IN@, Zoetis, Florham Park, New Jersey) may induce M cells overlying tonsils in the pharynx.

Wallace et al. (1995) compared the results of horses that were orally or intraperitoneally vaccinated with killed $S$. equi to non-immunized horses that were challenged with live virulent $S$. equi. Orally vaccinated horses were not as febrile or as sick as control, non-immunized horses, 
but intraperitoneally vaccinated horses did not become febrile or anorexic (Wallace et al. 1995). Only 2/4 intraperitoneally vaccinated horses developed submandibular abscessation, while 4/4 orally vaccinated horses developed submandibular abscessation although not to the degree of control horses (Wallace et al. 1995). Mucosal and systemic IgA and IgG were highest after challenge in the intraperitoneal group (Wallace et al. 1995).

Oral vaccinations have been used in other species to stimulate MALT. Use of the oral poliovirus vaccine established $99 \%$ eradication as it induced both systemic and mucosal immunity especially in the intestines where the virus multiplies and contributes to transmission (Behrend et al. 2014). An attenuated, gamma-irradiated Brucella neotomae administered orally to mice stimulated serum IgG and $\operatorname{IgM}$, mucosal $\operatorname{IgG}$, IgM, and $\operatorname{IgA}$, and antigen-specific $\mathrm{T}$ lymphocytes capable of secreting interferon (IFN)- $\gamma$ and tumor necrosis factor (TNF)- $\alpha$ (Dabral et al. 2014). This Brucella vaccine was protective against intraperitoneal and intranasal challenge compared to control mice (Dabral et al. 2014). Piglets that were immunized with oral ovalbumin (OVA) and adjuvant produced significantly more anti-OVA IgG, IgA, and IgM compared to OVA alone and control (Pasternak et al. 2014). This response indicated a successful systemic immune response to a mucosally-administered vaccine.

\section{Microsphere immunoassays}

Microsphere immunoassays (MIA) utilize fluorescent principles to detect analytes of interest. The microspheres (MagPlex ${ }^{\circledR}$ microspheres, Luminex Corp., Austin, Texas) are colorcoded with internal fluorescent dye ("region") allowing for utilization of multiple microspheres for the possibility of multiplexing an assay. In addition to color-coding, the microspheres are magnetized with internal iron particles containing magnetite. (Angeloni et al. 2016) The microspheres are coupled with proteins or oligonucleotides, and after incubation with samples, 
detection antibodies with fluorescence can be measured for the analyte of interest. The analyzer (Luminex Magpix ${ }^{\circledR}$, Luminex Corp., Austin, Texas) utilizes two light emitting diodes (LED) to excite fluorescence of the microsphere and a fluorescent dye. A red LED (511 nm) excites internal fluorescence of the microsphere itself, and a green LED (621 nm) excites fluorescent dye, typically phycoerythrin (PE). A charge-coupled device (CCD) imager then detects each individual microsphere and quantifies fluorescence of the dye in mean fluorescence intensity (MFI) (luminexcorp.com). A positive MFI response is 2 standard deviations above the negative control or background MFI (Angeloni et al. 2013).

\section{Microsphere coupling}

Proteins or immunoglobulins can be covalently bound to microspheres by a carbodiimide reaction as described by Angeloni, et al (2016). Carboxyl groups on the surface of microspheres are activated with 1-ethyl-3-[3-dimethylaminopropyl]carbodiimide hydrochloride (EDC) reagent. In the presence of sulfo-N-hydroxysulfosuccinimide (sulfo-NHS), this reaction forms a reactive sulfo-NHS-ester intermediate. The primary amine of the coupling molecule (antibody, protein) replaces the reactive intermediate and forms a covalent amide bond with the microsphere.

Immunoassays can be performed using indirect serologic assays, capture sandwich assays, or competitive assays depending on the capture molecule used and the analyte to be detected and measured.

\section{Advantages of microsphere immunoassays}

Compared to conventional assays such as ELISA and western blot (WB), microsphere immunoassays are advantageous because less sample volume is required, less time and cost are associated with analysis, greater sensitivity is possible with lower limits of detection and a 
broader range of quantification, and the ability to multiplex an assay is possible (ChristopherHennings et al. 2013; Baker et al. 2012). Compared to qualitative or semi-quantitative assays, the MIA can be quantitative by comparing sample MFI to standard curves. Because the color coding of the microsphere represents different "regions," these microsphere immunoassays can be multiplexed to allow to for potentially measuring up to 100-500 different analytes (luminexcorp.com). The major limitation for microsphere immunoassays is lack of veterinary species-specific antibodies to antibodies, as well as cytokines and chemokines.

\section{Development of standard curves for quantitative measurements}

A standard curve can be developed by utilizing a sample with a known analyte concentration. The known sample is diluted to known concentrations. For example, with a serum sample with a known IgG quantity of $14.6 \mathrm{mg} / \mathrm{ml}$ (Horse reference serum, Bethyl Laboratories, Montomery, Texas), 1:2 dilutions can be made to have expected concentrations of $0 \mathrm{ng} / \mathrm{ml}, 1.56 \mathrm{ng} / \mathrm{ml}, 3.12 \mathrm{ng} / \mathrm{ml}, 6.25 \mathrm{ng} / \mathrm{ml}, 12.5 \mathrm{ng} / \mathrm{ml}, 25 \mathrm{ng} / \mathrm{ml}, 50 \mathrm{ng} / \mathrm{ml}$, and $100 \mathrm{ng} / \mathrm{ml}$

(Table 2). MFI is measured for each of these standard dilution samples, and then analysis software can convert the measured MFI into concentrations in $\mathrm{ng} / \mathrm{ml}$ by using a non-linear curve fitting method. A common non-linear curve fitting method used is a five-parameter logistic (5PL). These non-linear curve fitting methods plot a log-linear relationship between MFI and analyte concentration to develop a sigmoidal response. The 5PL can allow for a degree of asymmetry associated with instrumentation and assay effects. Data fit to a 5PL are in the form:

$$
\mathrm{y}=\mathrm{b}+\left\{(\mathrm{A}-\mathrm{B}) /\left[1+(\mathrm{x} / \mathrm{c})^{\mathrm{D}}\right]^{\mathrm{E}}\right\}
$$

where: $\mathrm{A}=$ estimated response at infinite analyte concentration; $\mathrm{B}=$ estimated response at zero analyte concentration; $\mathrm{c}=$ concentration at sigmoidal inflection point; $\mathrm{D}=$ slope factor; and $\mathrm{E}=$ asymmetry factor. (Bates and Watts. 1988) 
When using a fluorescence imager like the Luminex Magpix® (Luminex Corp., Austin, Texas), analyst software (Milliplex ${ }^{\circledR}$, EMD Millipore, Billerica, Massachusetts) generates a standard curve using a 5PL. Once a standard curve is established, the unknown samples' MFI can be plotted on the curve to determine a concentration in $\mathrm{ng} / \mathrm{ml}$ (Figure 1).

Table 2: Data from serum with known $\mathrm{IgG}$ concentrations $(\mathrm{ng} / \mathrm{ml})$ used to generate a standard curve using Milliplex ${ }^{\circledR}$ analyst software (EMD Millipore, Billerica, Massachusetts).

\begin{tabular}{|c|c|c|c|c|c|c|c|}
\hline Location & $\begin{array}{c}\text { Expected } \\
n g / m l(i)\end{array}$ & MFI(i) & ng/ml(i) & MFI & $\mathrm{ng} / \mathrm{ml}$ & $\mathrm{CV}$ & Recovery \\
\hline $1 A 7$ & 0 & 192 & & 200.75 & & $4.36 \%$ & \\
\hline $1 \mathrm{~B} 7$ & & 209.5 & & & & & \\
\hline $1 \mathrm{C7}$ & 156 & 282 & 1.85 & 282.5 & 1.88 & $0.18 \%$ & $120.4 \%$ \\
\hline 107 & & 283 & 1.9 & & & & \\
\hline IE7 & 3.12 & 297 & 2.56 & 306.75 & 2.99 & $3.18 \%$ & $95.73 \%$ \\
\hline $1 F 7$ & & 316.5 & 3.39 & & & & \\
\hline $1 G 7$ & 6.25 & 372 & 5.46 & 367.5 & 5.31 & $1.22 \%$ & $84.9 \%$ \\
\hline $1 \mathrm{H} 7$ & & 363 & 5.15 & & & & \\
\hline $1 A 8$ & 12.5 & 719.5 & 14.16 & 716.75 & 14.11 & $0.38 \%$ & $112.84 \%$ \\
\hline 1B8 & & 714 & 14.05 & & & & \\
\hline $1 \mathrm{C} 8$ & 25 & 1389 & 24.44 & 1324 & 23.6 & $4.93 \%$ & $94.39 \%$ \\
\hline 108 & & 1258 & 22.73 & & & & \\
\hline $1 E 8$ & 50 & 4081 & 51.82 & 4032 & 51.36 & $1.22 \%$ & $102.71 \%$ \\
\hline 1F8 & & 3983 & 50.89 & & & & \\
\hline $1 G 8$ & 100 & 8038 & 99.05 & 8021 & 98.77 & $0.21 \%$ & $98.77 \%$ \\
\hline $1 \mathrm{H} 8$ & & 8005 & 98.5 & & & & \\
\hline
\end{tabular}


Figure 1: Standard curve generated using Milliplex ${ }^{\circledR}$ analyst software (EMD Millipore, Billerica, Massachusetts)

\section{B[Analyte 55]}

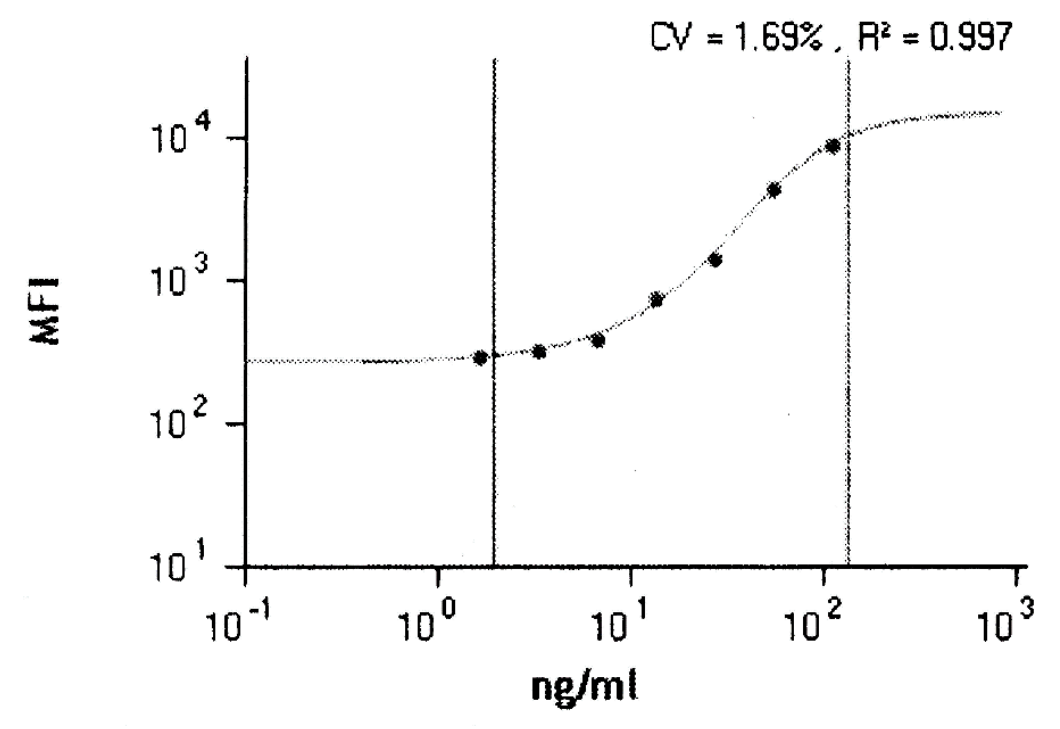

\section{Microsphere immunoassays utilized in equine veterinary medicine}

Microsphere immunoassays have been developed to quantify equine cytokines with a multiplex assay. Wagner and Freer (2009) developed a multiplex assay for analysis of equine interleukin (IL)-4, IL-10, and IFN- $\alpha$. These cytokines were coupled to three different bead regions. Compared to ELISA, the multiplex assay had between 13- to 150-fold improved sensitivity (Wagner and Freer. 2009). More recently a multiplex for six cytokines was described (Hall et al. 2015). This assay detected IL-2, IL-4, IL-6, IL-10, IFN- $\gamma$, and TNF- $\alpha$ with good sensitivity (ranging from 1.9 to $40.8 \mathrm{pg} / \mathrm{ml}$ ) and low cross-reactivity (ranging from $0.1-15 \%$ ) (Hall et al. 2015).

Microsphere immunoassays have been developed to detect serologic responses to a variety of equine diseases including West Nile virus (WNV) (Balasuriya et al. 2006), flavivirusassociated neurologic diseases (Beck et al. 2015), equine viral arteritis (Go et al. 2008), African 
horse sickness (Sanchez-Matamoros et al. 2015), Lyme disease (Wagner et al. 2011), and Hendra virus (McNabb et al. 2014). An MIA incorporating recombinant WNV envelope protein (rE) was found to have diagnostic sensitivity and specificity (99.3\% and $97.4 \%$, respectively) compared to plaque reduction neutralization test (PRNT) (Balasuriya et al. 2006). Recombinant WNV nonstructural proteins (rNS) 1, 3, and 5 MIA were less sensitive (0-48.0\%) (Balasuriya et al. 2006). The rE MIA is advantageous compared to the PRNT because it is more convenient, rapid, and does not use live virus and would be useful for large scale surveillance. A serologic multiplex assay for flavivirus-associated neurologic disease in horses including WNV, Japanese encephalitis virus (JEV), and tick-borne encephalitis virus (TBEV) was compared to virus neutralization titers (VNTs) (Beck et al. 2015). The envelope (E) protein of flaviviruses is highly immunogenic and was used as either soluble ectodomain of $\mathrm{E}(\mathrm{sE})$ or envelope domain III (EDIII) for covalently binding to microspheres. A positive TBEV.EDIII signal indicated infection of a horse with TBEV. A positive WNV.EDIII or JEV.EDIII signal could indicate infection with WNV or JEV infection. These findings indicate no cross reactivity of EDIII during TBEV infection and slight cross reactivity of EDIII between JEV and WNV (Beck et al. 2015). An MIA detecting equine arteritis virus (EAV) antibodies was compared to VNT (Go et al. 2008). Microspheres coupled with partial glycoprotein (GP) $555-98$ had a sensitivity and specificity of $93.1 \%$ and $93.9 \%$ compared to VNT. The MIA results correlated significantly to VNT; but sera with low antibody titers (1:4 and 1:8) gave false negative results on MIA indicating that the MIA can only detect higher titers (>/= 1:16) to EAV reliably (Go et al. 2008). An MIA to detect African horse sickness (AHS) anti-viral particle (VP) 7 antibodies was developed and compared to commercial ELISA and lateral flow assay (LFA) kits for detection of anti-VP7 antibodies (Sanchez-Matamoros et al. 2015). The MIA was found to have a lower 
limit of detection compared to commercial kits indicating it is more sensitive, and the MIA had similar specificity to the ELISA while the LFA was unreliable (Sanchez-Matamoros et al. 2015). A multiplex MIA utilizing three outer surface proteins (Osp) of Borrelia burgdorferi was developed to determine vaccination versus early or chronic infection (Wagner et al. 2011). OspC antibodies were found during early infection and OspF antibodies were found with chronic infection (Wagner et al. 2011). OspA antibodies are found with vaccination as in humans. Compared to the "relative" gold standard of WB, the multiplex MIA had improved sensitivity with antibody detection by the MIA in $\mathrm{pg} / \mathrm{ml}$ compared to the WB in $\mu \mathrm{g} / \mathrm{ml}$ (Wagner et al. 2011). The MIA provided a quantitative measurement compared to WB which would be useful for treatment response; and the MIA is more specific than quantitative ELISA tests. Lastly, an MIA for Hendra virus was developed and compared to ELISA and VNT (McNabb et al. 2014). A recombinant glycoprotein ( $\mathrm{sG}$ ) which is more soluble was coupled to microspheres. The MIA was found to be sensitive and specific with exception to Nipah virus (McNabb et al. 2014). 


\section{Chapter 3 - Materials and Methods}

\section{Subject selection and treatment allocation}

Eight healthy adult horses belonging to the Kansas State University College of Veterinary Medicine (CVM) teaching herd were used for this study. Horses in the teaching herd were closed to contact with outside horses throughout the course of investigation. The decision to use CVMowned horses was twofold. Horses considered for study were members of the CVM teaching herd for a minimum of 2 years, which assured that they did not suffer from S. equi infection or receive vaccination prior to investigation. Additionally, it was preferred that CVM horses were used for to avoid the potential for adverse reaction (e.g. purpura hemorrhagica) from occurring in privatelyowned horses. Ages ranged from 5-23 years (mean $=15$ years) with body weights between 386$603 \mathrm{~kg}($ mean $=526 \mathrm{~kg})$ in horses selected for investigation. These horses were randomly assigned to receive either Streptococcus equi subsp. equi (Pinnacle IN®, Zoetis, Florham Park, New Jersey) vaccination by the intranasal or oral route ( $\mathrm{n}=4$ horses each). Horses received initial vaccination on Day 0, and a booster vaccination 3 weeks later on Day 21, consistent with manufacturer guidelines (Figure 3). Horses were maintained in individual stalls for 3 days following vaccination treatment to reduce the potential for nose-to-nose contact with any other horses following vaccination (Harms et al. 2014). After being housed individually, horses were maintained in a stall with run environment.

For the duration of the experiment, horses received $2 \%$ of their body weight in prairie grass hay daily with water available free choice and concentrate supplementation as needed. No feeding changes were made as a component of this investigation; horses were fed and maintained following routine management of the teaching herd of horses at Kansas State University College of 
Veterinary Medicine. Approval for this project was granted by the KSU Institutional Animal Care and Use Committee (IACUC \#3285.1).

\section{Inclusion criteria and sample collection}

Consistent with CONSORT vaccine trial guidelines, thirteen CVM teaching herd horses were examined for eligibility. Inclusion criteria for this study included horses younger than 25 years of age, determined to be healthy based on physical examination and baseline blood work (complete blood count and serum biochemistry), and that had a Streptococcus equi M protein (SeM) titer <1:1600 considered to be immunologically naïve with no history of previous vaccination or exposure/infection in at least the previous 24 months. The decision for selecting horses that had a SeM protein titer of $<1: 1600$ was based on the current standard of practice in accordance with the American College of Veterinary Internal Medicine S. equi consensus statement (Sweeney et al. 2005). Eight out of thirteen horses were selected to be included in the vaccine trial and were randomly allocated to receive either intranasal or oral vaccination (Figure 2). 
Figure 2: Experimental animals

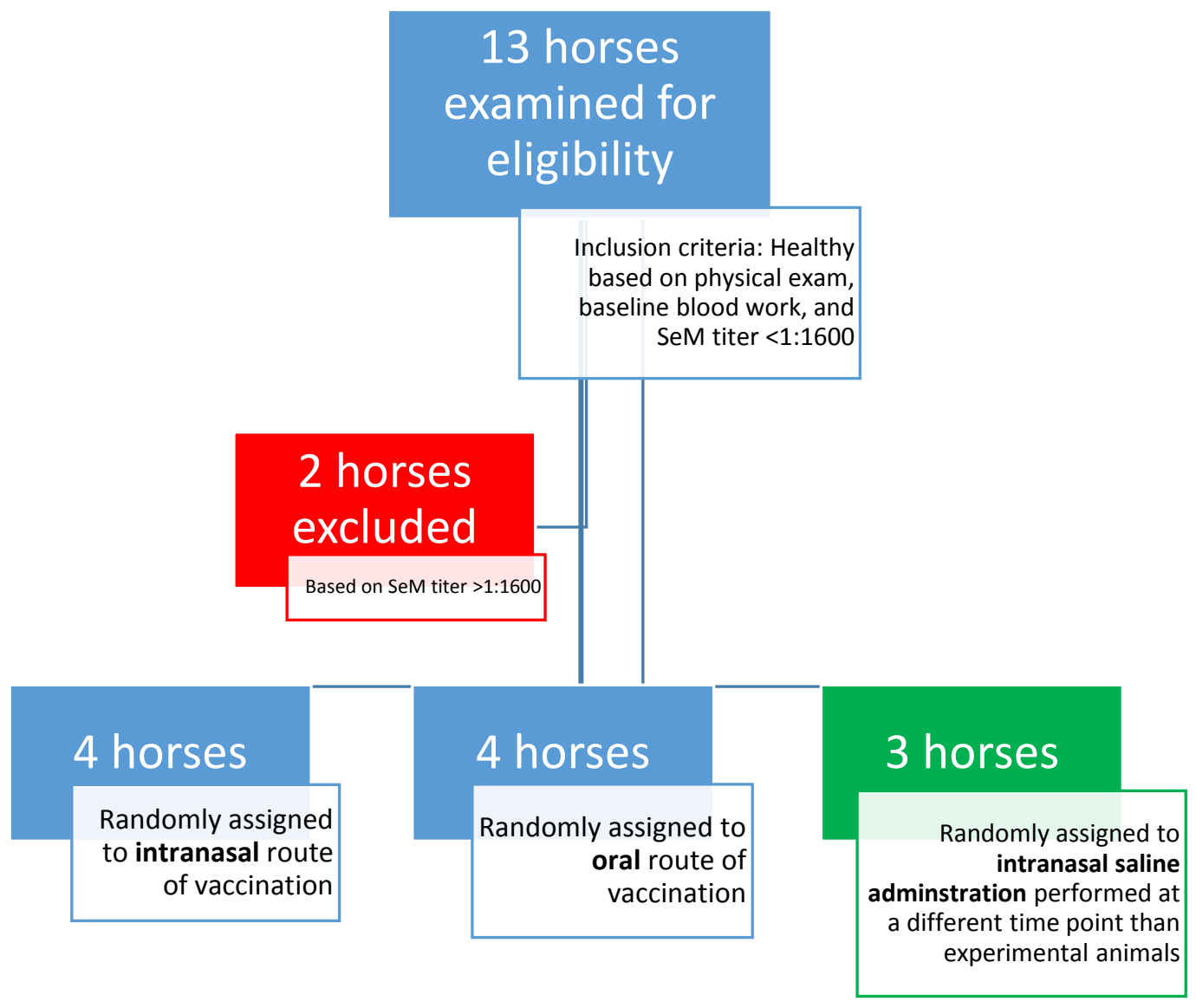

Host immunity was assessed via systemic and local SeM-specific humoral immune responses measured prior to and after vaccination. Recall that vaccine was administered by 2 different mucosal routes; consistent with previous equine studies aimed at detection of humoral immune activation, a detectable level of antibody secretion present in nasal secretions was expected by 2 weeks following vaccination (Nelson et al. 1998). Also, based on known kinetics of primary and anemnestic host immune responses, a 4 week sampling interval following booster vaccination was selected to measure a serum immunoglobulin response (Nelson et al. 1998; Tizard. 2013). Therefore, at two and four weeks post-booster vaccination, nasal secretion and serum samples were obtained from each horse (Figure 3). Whole blood and serum were collected 
via jugular venipuncture. Samples were centrifuged (3700 rpm for 10 minutes), aliquoted, and frozen at -80 degrees $\mathrm{C}$ until analysis.

Figure 3: Experimental timeline

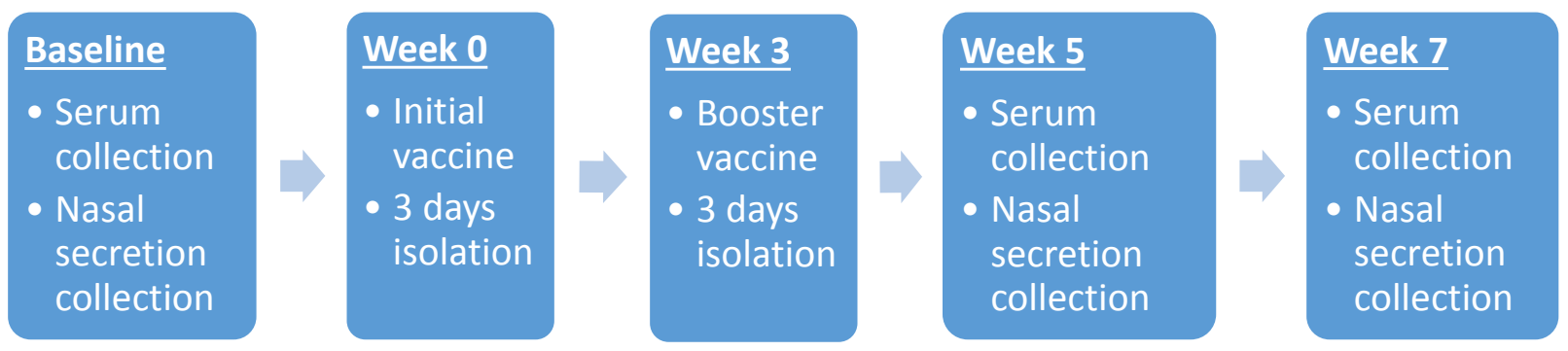

For collection of nasal secretion samples, horses were sedated with xylazine ${ }^{\mathrm{b}}(0.5 \mathrm{mg} / \mathrm{kg}$ IV). A 4x4 gauze square was prepared as the nasal secretion collection device by rolling it cylindrically and applying an adhesive strip for detainment. The gauze was placed in the ventral nasal meatus of each horse, approximately 2 inches from the nostril opening and left in place for 20 minutes to allow for absorption of nasal secretions. This procedure was adapted from that described in horses (Nelson et al. 1998) and cattle (McKercher et al. 1973) to collect undiluted nasal secretions. The gauze square was then placed in a $50 \mathrm{~mL}$ conical tube. Once transported back to the laboratory, samples were spun down (2000 rpm for 30 minutes) to concentrate secretions. The collected nasal secretions were aliquoted and frozen at -80 degrees $\mathrm{C}$ until analysis.

Complete blood count and serum biochemistry samples were conducted at the clinical pathology laboratory at Kansas State University Veterinary Diagnostic Laboratory, and titers for 
serum IgG against SeM were quantified using an ELISA assay (Equine Diagnostic Solutions, LLC, Lexington, Kentucky).

Serum and nasal secretion samples were tested for SeM-specific IgA immunologic response to vaccination using magnetic microspheres in a modified sandwich ELISA method described below.

\section{Protein coupling to magnetic microspheres}

Carboxylated magnetic microspheres (microsphere bead 48) were coated with Streptococcus equi subsp. equi M protein via a carbodiimide reaction (Figure 4: A). The protocol was supplied by Luminex ${ }^{\circledR}$ laboratories (Luminex Corp., Austin, Texas), as previously reported (Baker et al. 2012) and used $5 \mu \mathrm{g}$ of recombinant protein (kindly provided courtesy of Dr. John Timoney, Gluck Equine Research Center, University of Kentucky, Lexington, Kentucky) per $1 \times 10^{6}$ microspheres. The concentration of $5 \mu \mathrm{g} / 1 \times 10^{6}$ microspheres was used based on titrations of $2.5 \mu \mathrm{g}, 5 \mu \mathrm{g}$, and $10 \mu \mathrm{g} / 1 \times 10^{6}$ microspheres using a negative serum sample (pre-vaccination SeM-specific IgG titer of 1:800) and a positive serum sample (post-vaccination SeM-specific IgG titer of 1:6400) (Figure 5). 
Figure 4: Microsphere labeling. Magnetic microspheres coated with SeM protein (A). Experimental samples (B) incubated with microspheres. Analyte detection with a secondary goat anti-horse $\operatorname{IgA}$ antibody (C) and detection PE-conjugated donkey anti-goat $\operatorname{IgG}(\mathrm{D})$.



Figure 5: $M$ protein coupling titration. Negative pre-vaccination serum sample and positive postvaccination serum sample used for three different $M$ protein concentration $\left(2.5 \mu \mathrm{g} / 1 \times 10^{6}\right.$ microspheres, $5 \mu \mathrm{g} / 1 \times 10^{6}$ microspheres, and $10 \mu \mathrm{g} / 1 \times 10^{6}$ microspheres).

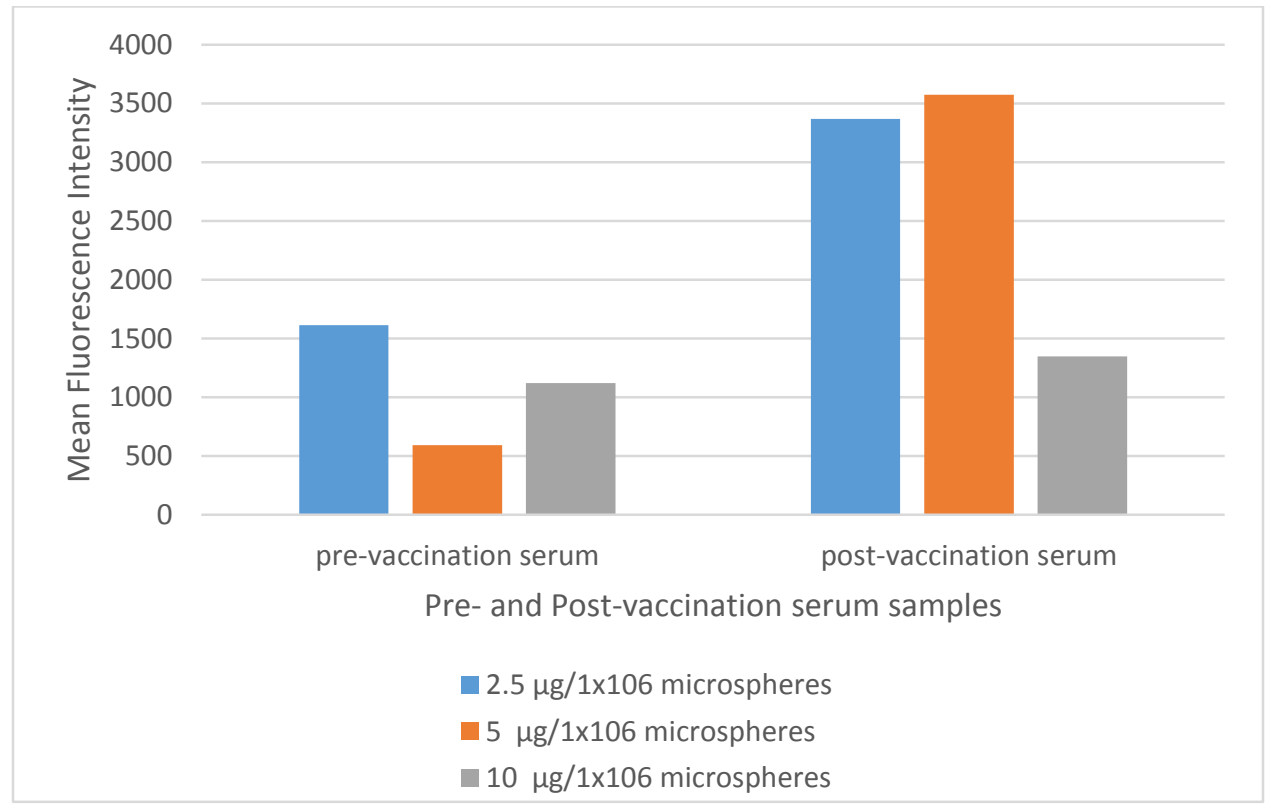


Protein coupling to microspheres was confirmed by comparing pre-coupling $\mathrm{M}$ protein solution to post-coupling microsphere supernatant to a bovine serum albumin (BSA) standard curve (Figure 6). A BSA standard sample (2 mg/ml) (Thermo Fisher Scientific Inc., Rockford, Illinois) was diluted to known concentrations: $0 \mu \mathrm{g} / \mathrm{ml}, 50 \mu \mathrm{g} / \mathrm{ml}, 100 \mu \mathrm{g} / \mathrm{ml}, 200 \mu \mathrm{g} / \mathrm{ml}, 400$ $\mu \mathrm{g} / \mathrm{ml}, 600 \mu \mathrm{g} / \mathrm{ml}, 800 \mu \mathrm{g} / \mathrm{ml}, 1000 \mu \mathrm{g} / \mathrm{ml}, 1200 \mu \mathrm{g} / \mathrm{ml}$, and $1400 \mu \mathrm{g} / \mathrm{ml}$. Each standard dilution and sample (pre-coupling $\mathrm{M}$ protein solution and post-coupling microsphere supernatant) was aliquoted $(50 \mu \mathrm{L})$ in duplicate wells to a flat, clear-bottom 96 well plate. A working solution (Thermo Fisher Scientific Inc., Rockford, Illinois) of 1 part Reagent A (containing sodium carbonate, sodium bicarbonate, bicinchoninic acid (BCA), and sodium tartrate in $0.1 \mathrm{M}$ sodium hydroxide) and 49 parts Reagent B (4\% cupric sulfate) (1:50 dilution) was made, and $200 \mu 1$ of this working solution was added to each well. This method uses the reduction of $\mathrm{Cu}^{+2}$ to $\mathrm{Cu}^{+1}$ by the biuret reaction. Detection of the $\mathrm{Cu}^{+1}$ is by chelation of the reagent containing two molecules of BCA with one cuprous ion resulting in a purple-colored reaction (Pierce BCA Protein Assay Kit, thermofisher.com). The plate was incubated in the dark at room temperature for 1 hour to allow for this reaction to occur. The plate was then read on a spectrophotometer at A550 nm. The standard curve (Figure 6) was generated with the linear slope-intercept equation:

$$
\mathrm{y}=0.0001 \mathrm{x}+0.1203
$$

where $\mathrm{y}=$ absorbance and $\mathrm{x}=$ concentration $(\mu \mathrm{g} / \mathrm{ml})$

The pre-coupling $\mathrm{M}$ protein solution had an absorbance of 0.243 resulting in a concentration of $1227 \mu \mathrm{g} / \mathrm{ml}(1.2 \mathrm{mg} / \mathrm{ml})$, and the post-coupling $\mathrm{M}$ protein solution had an absorbance of 0.147 resulting in a concentration of $267 \mu \mathrm{g} / \mathrm{ml}(0.267 \mathrm{mg} / \mathrm{ml})$. The binding efficiency was found to be $77.8 \%$ and confirmed coupling of the M protein to the microspheres. 
Figure 6: BSA standard curve

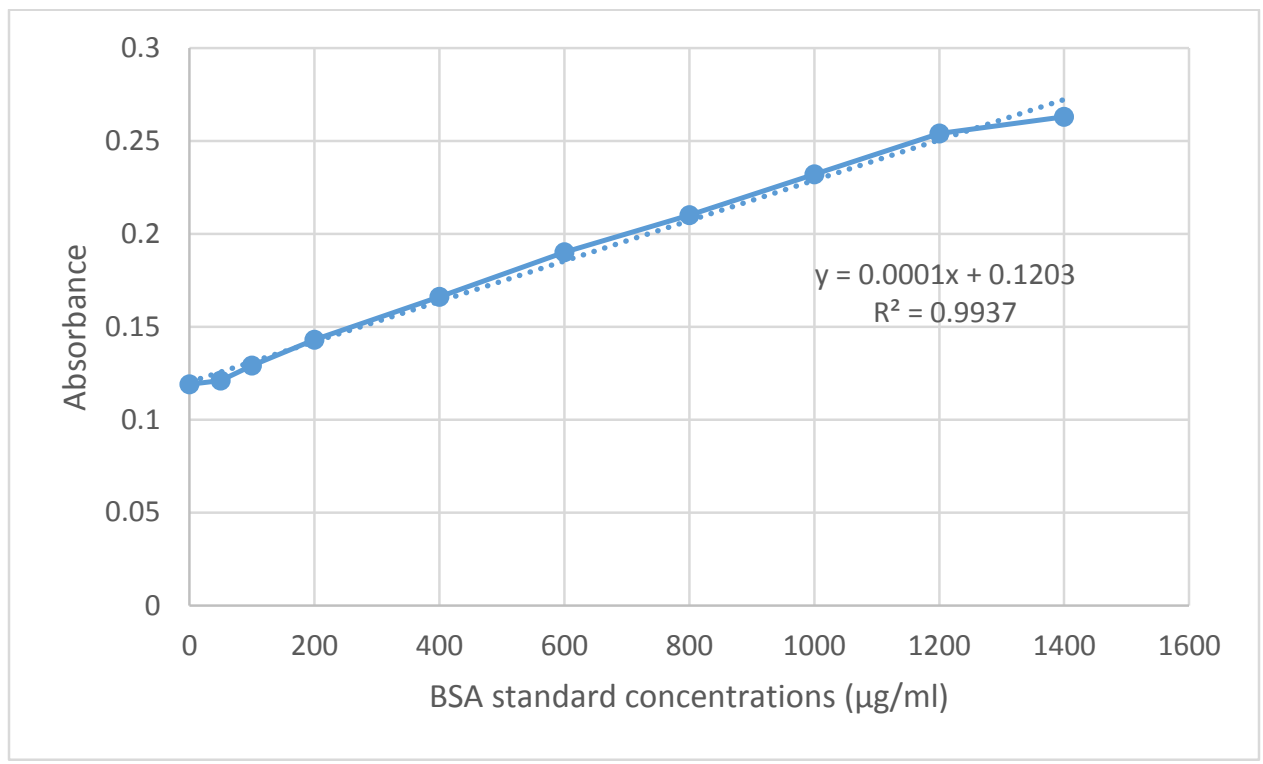

The SeM protein-specific IgA assay as described below was validated by using a negative control of bovine serum and a positive control of a horse with a robust response to vaccination (serum SeM-specific IgG titer of 1:6400). Mean fluorescence intensities (MFI) were measured and considered relative SeM-specific IgA quantifications. Despite background MFI in the pre, 2week, and 4-week post vaccination serum or nasal secretions samples, assessing both pre and post MFI measurements for each sample allowed for appropriate comparison and statistical analysis. MFI is not meant to be a measurement of absolute immunoglobulin concentration and cannot be correlated to immunoglobulin concentration at this point.

\section{Quantitation (in MFI) of SeM protein-specific IgA}

A 96 well plate map was prepared for replicate dilutions of experimental serum and nasal secretion samples. Dilutions used for both nasal secretion and serum samples were optimized at approximately 1:50 for SeM protein-specific IgA detection. A working solution of microspheres was prepared in phosphate-buffered solution (PBS) to allow for 5000 microspheres per well and 
$50 \mu \mathrm{L}$ per well. SeM protein-coated Region 48 microspheres were incubated with serum or nasal secretion samples (Figure 4: B).

Serum or nasal secretion samples, including a blank negative control, and microsphere solution were aliquoted into each of the appropriate wells at $50 \mu \mathrm{L}$ per well each. The plate was then sealed, protected from light, placed on a plate shaker, and allowed to incubate overnight at 4 degrees $\mathrm{C}$. The plate was then washed by placing it in the plate magnet for 1 minute, decanting the supernatant, and resuspending the microspheres in each well with $100 \mu \mathrm{L} \mathrm{PBS}$. The wash step was repeated twice. The microspheres were resuspended out of the plate magnet with $50 \mu \mathrm{L}$ PBS per well. A secondary antibody solution was prepared to allow for $50 \mu \mathrm{L}$ per well using goat antihorse IgA (Bethyl Laboratories Inc., Montgomery, Texas) at a concentration of $4 \mu \mathrm{g} / \mathrm{mL}$ (Figure 4: C). The plate was again sealed, protected from light, placed on a plate shaker, and allowed to incubate for 1 hour. The plate was washed again 3 times. A detection antibody solution was prepared to allow for $50 \mu \mathrm{L}$ per well using pycoerythrin-conjugated donkey anti-goat IgG(Thermo Fisher Scientific Inc., Rockford, Illinois) at a concentration of $4 \mu \mathrm{g} / \mathrm{mL}$ (Figure 4: D). The concentration of $4 \mu \mathrm{g} / \mathrm{ml}$ was chosen based on standard curve titrations using $1 \mu \mathrm{g} / \mathrm{ml}, 5 \mu \mathrm{g} / \mathrm{ml}$, and $10 \mu \mathrm{g} / \mathrm{ml}$ (Figure 7). The plate was incubated similarly for 30 minutes. The plate was washed three times and the microspheres were resuspended one final time with $100 \mu \mathrm{L}$ of PBS per well. 
Figure 7: Detection donkey anti-goat IgG antibody titrations of $1 \mu \mathrm{g} / \mathrm{ml}, 5 \mu \mathrm{g} / \mathrm{ml}$, or $10 \mu \mathrm{g} / \mathrm{ml}$ using an IgG standard curve.

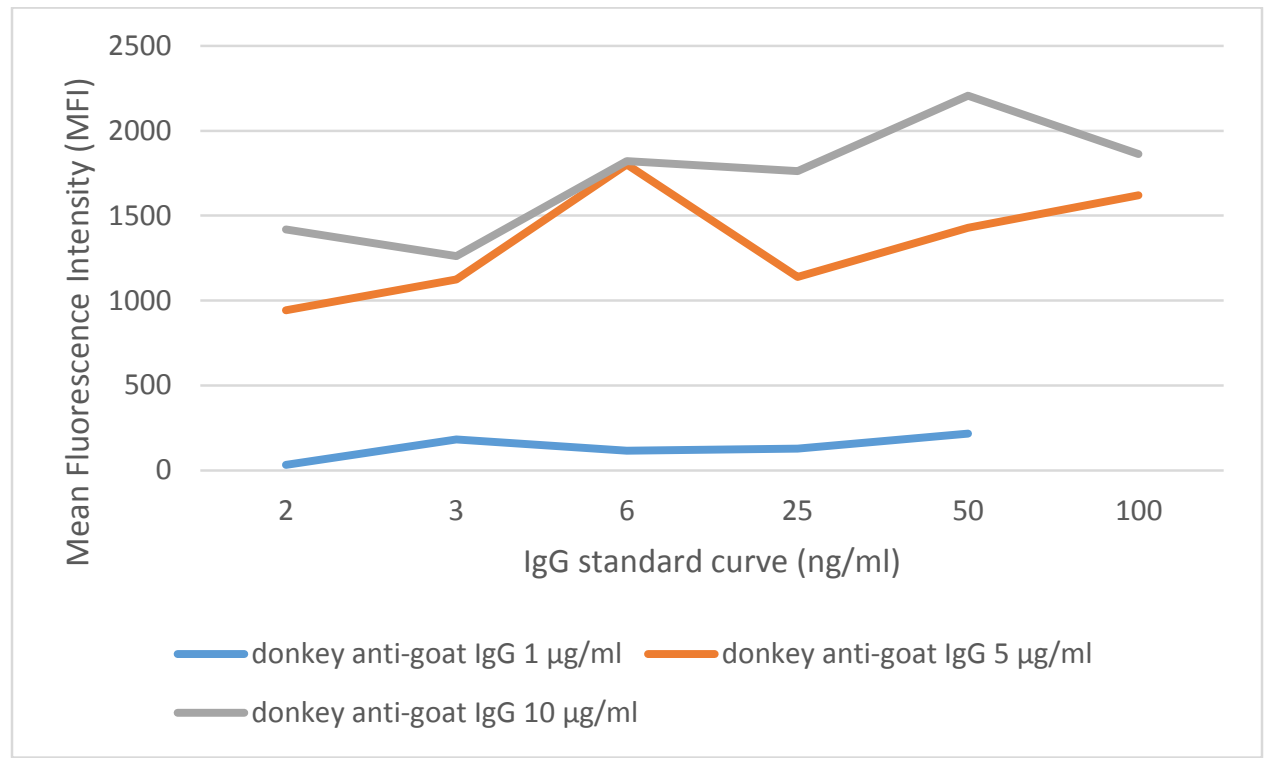

The data acquisition protocol was analyzed using the Luminex MagPix® (Luminex Corp., Austin, Texas). The MFI reported by the Luminex MagPix ${ }^{\circledR}$ (Luminex Corp., Austin, Texas) were used as a measure of relative IgA quantification for each sample.

\section{Statistical Analysis}

Each of the responses, namely serum IgG SeM titers, as well as serum and nasal secretion SeM-specific IgA (measured in MFI) was expressed in the natural log scale and fitted with a general linear mixed model. The linear predictor in the model included the fixed effects of treatment (oral vs. intranasal administration), time (pre-vaccination and post-vaccination time point) and their 2-way interaction. The random effect of horse nested within treatment was fitted to the model to identify the experimental unit for treatment and the unit of repeated observations over time. 
Kenward Roger's procedure was used to estimate degrees of freedom and adjust estimated standard errors. Model assumptions were evaluated using externally studentized residuals and were considered to be reasonably met.

Statistical models were fitted using the GLIMMIX procedure of SAS (SAS Version 9.4, SAS Institute, Cary, North Carolina) implemented using Newton-Raphson with ridging as the optimization technique. Estimated least square means and 95\% confidence intervals are presented in the original scale of the data. Relevant pairwise comparisons were conducted using Bonferroni adjustment, as appropriate in each case to avoid inflation of Type I error rate due to multiple comparisons. 


\section{Chapter 4 - Results}

Immediately prior to the start of the study, there was no evidence for differences in serum IgG SeM titers (Equine Diagnostic Solutions, LLC, Lexington, Kentucky) between horses assigned to receive intranasal or oral vaccination (Figure 8; $\mathrm{P}=0.83$ ); neither was there any evidence for differences in relative SeM-specific IgA expression (in MFI) in serum or nasal secretions between groups (Figures 9 and $10 ; \mathrm{P}=0.93$ and $\mathrm{P}=0.37$, respectively). This is consistent with the expectation that horses recruited for this pilot study were previously unvaccinated and immunologically naïve to $S$. equi.

Two weeks following vaccination, an increase in serum SeM-specific IgA (in MFI) was apparent for intranasally-vaccinated horses only (Figure 9; $\mathrm{P}=0.0068$ ); in turn, horses vaccinated through the oral route showed no evidence of changes in serum SeM-specific IgA (Figure 9; $\mathrm{P}=0.1504)$. Moreover, serum SeM-specific IgA levels by 2 weeks after vaccination were greater for horses vaccinated via the intranasal route than those vaccinated by the oral route (Figure 9; $\mathrm{P}=0.03$ ). Regarding nasal secretion of SeM-specific $\mathrm{IgA}$, neither group showed any evidence for changes from baseline to 2 weeks after the vaccine series (Figure 10; $\mathrm{P}=0.627$ ).

By 4 weeks following completion of the 2-dose vaccination series, all vaccinated horses showed a significant increase in serum IgG SeM titer (Equine Diagnostic Solutions, LLC, Lexington, Kentucky) regardless of route of vaccination (Figure 8; $\mathrm{P}=0.0132$ ); however, the increase was substantially greater for horses vaccinated by the intranasal route $(\mathrm{P}=0.0006)$ compared with those vaccinated orally (Figure $8 ; \mathrm{P}=0.0150$ ). The magnitude of the increase in IgG SeM titer relative to baseline was estimated at approximately 10 -fold for the intranasallyvaccinated horses, and at approximately 3 -fold for the orally vaccinated horses. 
Figure 8: Least square mean estimates (and corresponding 95\% confidence intervals) of serum IgG SeM titer (Equine Diagnostic Solutions, LLC, Lexington, Kentucky) at baseline prior to vaccination (week 0) and 4 weeks following a 2-dose vaccine series (week 7) for horses vaccinated via intranasal (purple diamond symbols) or oral (red cross symbols) routes. Arrows indicate time of vaccine administration. ${ }^{\mathrm{x}, \mathrm{y}}$ Different letters indicate differences $(\mathrm{P}<0.05)$ from baseline to 7 weeks into the study (i.e. 4 weeks post-booster) within each vaccination group. ${ }^{\text {a,b }}$ Different letters indicated difference $(\mathrm{P}<0.05)$ between intranasal and oral vaccinates at 7 weeks into the study. Point estimates were jittered horizontally to allow for clear visualization.

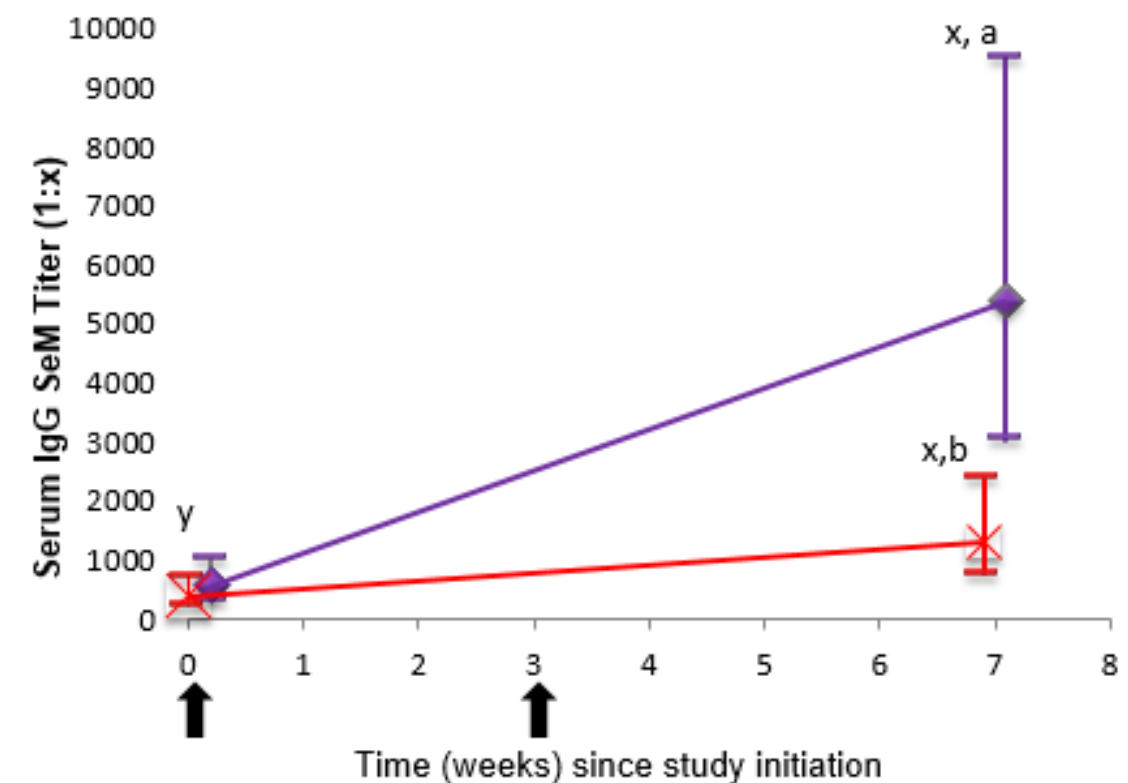

Figure 9: Least square mean estimates (and corresponding 95\% confidence intervals) of serum SeM-specific IgA (in MFI) at baseline prior to vaccination (week 0) and 2 weeks following a 2 dose vaccine series (week 5) for horses vaccinated via the intranasal (purple diamond symbols) or oral (red cross symbols) routes. Arrows indicate time of vaccine administration. ${ }^{a, b}$ Different 
letters indicated difference $(\mathrm{P}<0.05)$ between intranasal and oral vaccinates at 5 weeks into the study. Point estimates were jittered horizontally to allow for clear visualization.

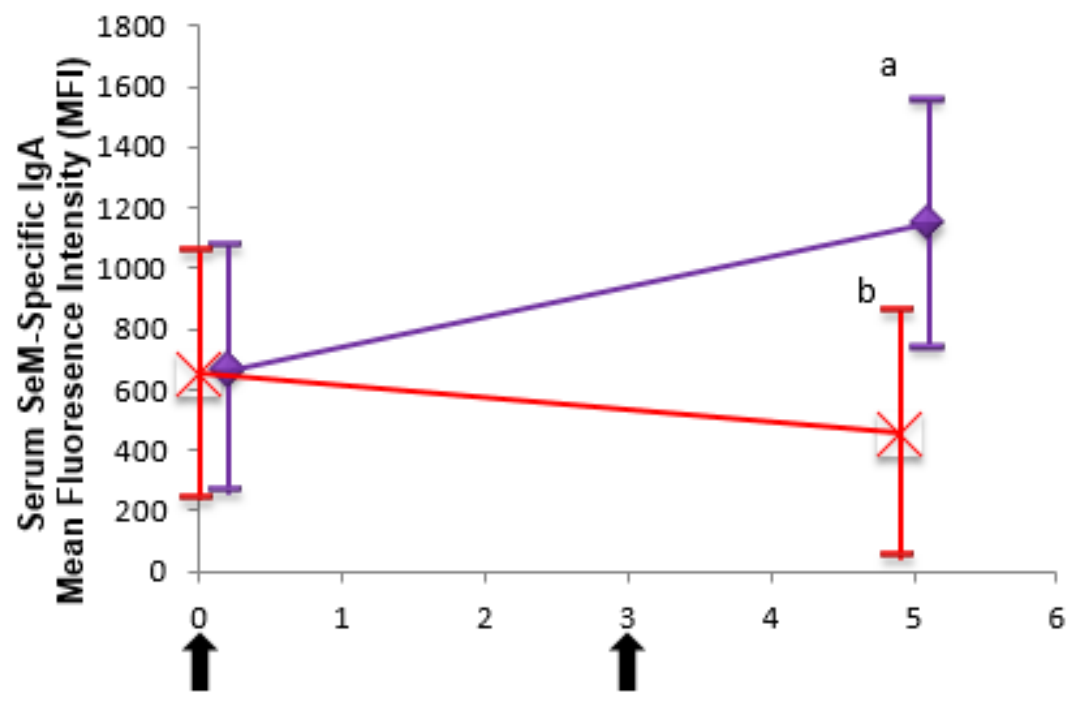

Time (weeks) since study initiation

Figure 10: : Least square mean estimates (and corresponding 95\% confidence intervals) of nasal secretion SeM-specific IgA (in MFI) at baseline prior to vaccination (week 0) and 2 weeks following a 2-dose vaccine series (week 5) for horses vaccinated via the intranasal (purple diamond symbols) or oral (red cross symbols) routes. Arrows indicate time of vaccine administration. Point estimates were jittered horizontally to allow for clear visualization.



Time (weeks) since study initiation 


\section{Chapter 5 - Discussion}

In the current report, horses were vaccinated with a USDA-approved, live-attenuated $S$. equi vaccine (Pinnacle IN®, Zoetis, Florham Park, New Jersey) either via the licensed intranasal route or via the oral route. Results confirmed that horses vaccinated using the licensed intranasal route had a substantial increase in both serum SeM-specific $\operatorname{IgG}$ and $\operatorname{IgA}$ antibody levels postvaccination. Although a significant mean increase in IgG SeM titers were observed, it was noted that a considerable amount of variability was observed amongst horses, probably due to individual host immune responsiveness. Horses that were vaccinated using the oral route also showed an increase in the serum IgG SeM protein antibody level post-vaccination, but not to the same magnitude as intranasally-vaccinated horses. Orally-vaccinated horses also did not show evidence for any response in serum SeM-specific IgA following vaccination. Horses vaccinated with intranasal saline did not show evidence of change in serum IgG SeM titer, serum SeM-specific $\operatorname{IgA}$, or nasal secretion SeM-specific IgA (Figures 11, 12, and 13, respectively) from pre- to postvaccination indicating the source of immunologic response in experimental horses was vaccine administration.

Figure 11: Least square mean estimates (and corresponding 95\% confidence intervals) of serum IgG SeM titer (Equine Diagnostic Solutions, LLC, Lexington, Kentucky) at baseline prior to vaccination (week 0 ) and 4 weeks following a 2-dose vaccine series (week 7) for horses vaccinated with intranasal saline. Arrows indicate time of vaccine administration. Intranasal saline 
vaccination was performed at a separate time point than experimental animal vaccinations; therefore, direct comparison between this group and experimental animals could not be performed.



Figure 12: Least square mean estimates (and corresponding 95\% confidence intervals) of serum SeM-specific IgA (in MFI) at baseline prior to vaccination (week 0) and 2 weeks following a 2dose vaccine series (week 5) for horses vaccinated with intranasal saline. Arrows indicate time of vaccine administration. Intranasal saline vaccination was performed at a separate time point than experimental animal vaccinations; therefore, direct comparison between this group and experimental animals could not be performed. 


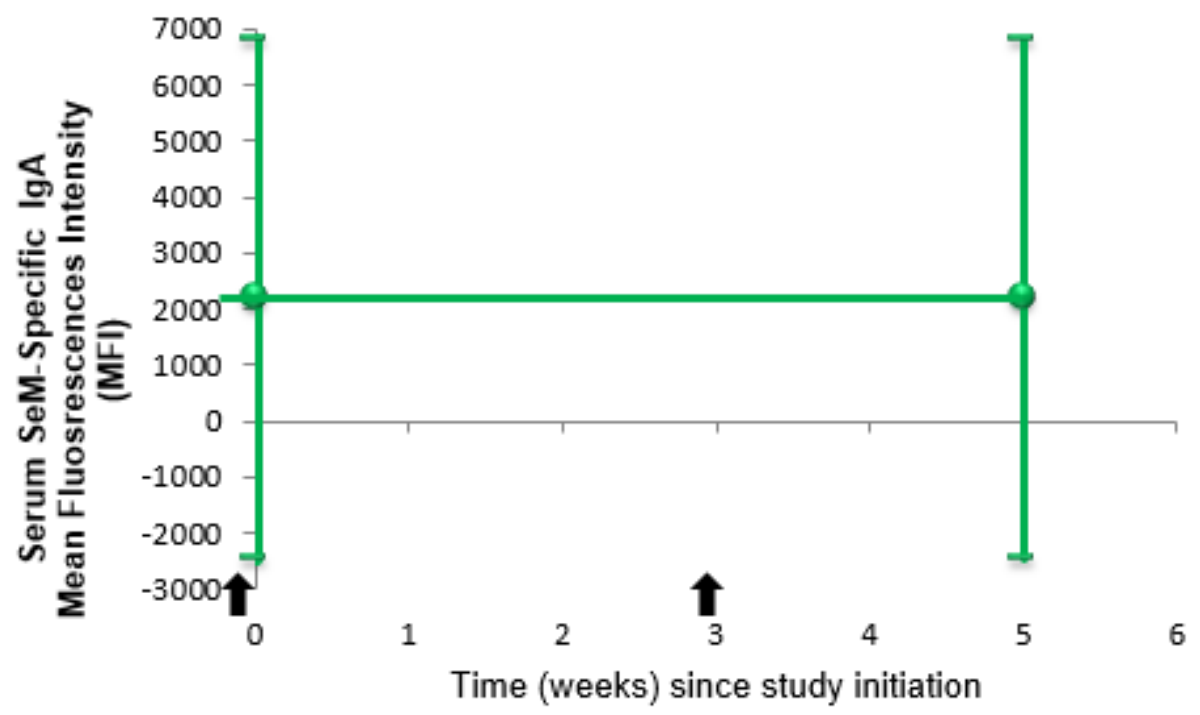

Figure 13: Least square mean estimates (and corresponding 95\% confidence intervals) of nasal secretion SeM-specific IgA (in MFI) at baseline prior to vaccination (week 0) and 2 weeks following a 2-dose vaccine series (week 5) for horses vaccinated with intranasal saline. Arrows indicate time of vaccine administration. Intranasal saline vaccination was performed at a separate time point than experimental animal vaccinations; therefore, direct comparison between this group and experimental animals could not be performed.

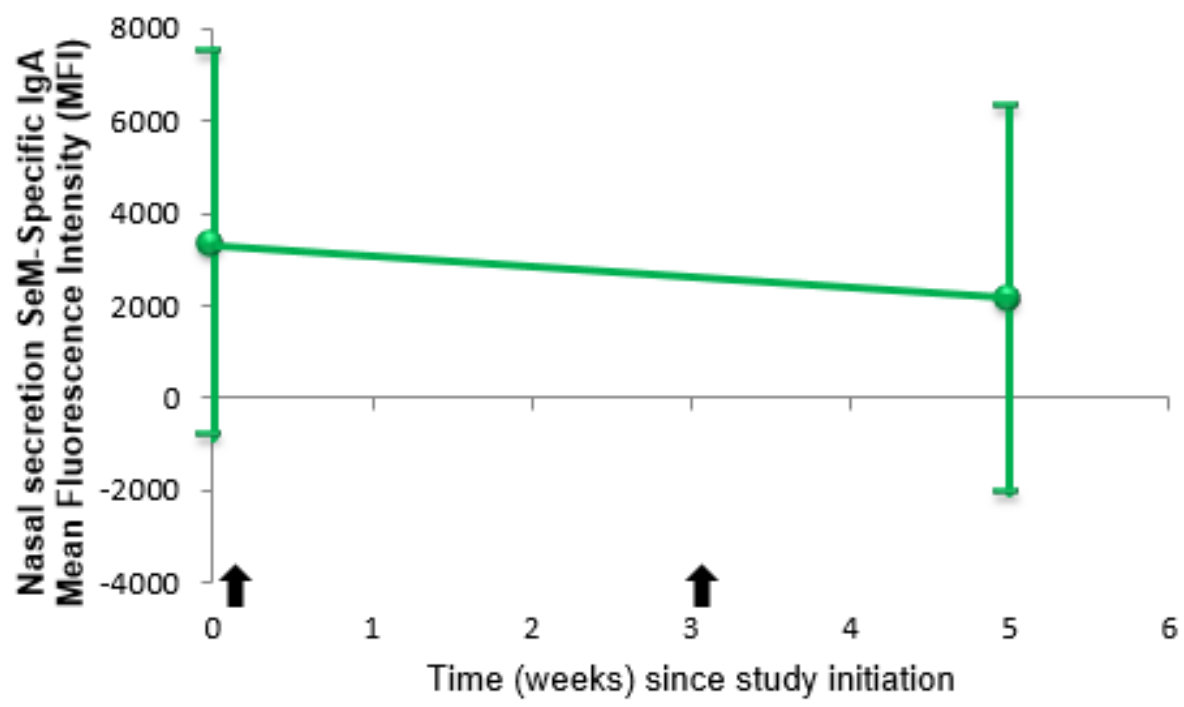


Convalescent horses have been shown to develop a strong serum IgGb response to specific virulence factors of $S$. equi, in particular surface proteins (SeM), as well as strong SeM-specific mucosal IgA and IgGb responses (Galan and Timoney. 1985; Sheoran et al. 1997). Further, IgA in convalescent horses was first detected at 3 weeks post-challenge (Sheoran et al. 1997). However, neither the intranasal nor the oral routes of vaccination elicited significant changes in nasal secretion SeM-specific IgA response in this study. These results contrast with those of Timoney (2004), who provided evidence that the attenuated intranasal S. equi vaccine induced both systemic and mucosal antibody responses. Changes in mucosal antibody responses may not have been identified in this study because of small changes in antibody response or timing of sample collection (i.e. if samples were collected before detectable IgA production). Also the method of nasal secretion collection used in this study may not have yielded as significant amounts of $\operatorname{IgA}$ as compared to other sampling methods like nasopharyngeal washes (Sheoran et al. 1997).

The oral route of administration is aimed at exposing the pharyngeal tonsils to liveattenuated bacteria, which is expected to effectively enhance local mucosal antibody expression. Yet, previous work has demonstrated that different routes of immunization evoke immunologic responses in different systems of the body (Holmgren and Czerkinsky. 2005). Oral administration is known to evoke antibody responses in the intestines, mammary and salivary glands in humans; whereas, nasal immunization results in antibody response in the upper airway mucosa and regional salivary and nasal secretions (Holmgren and Czerkinsky. 2005). A previous study evaluated oral administration of a killed $S$. equi vaccine compared to intraperitoneal administration to control horses after challenge (Wallace et al. 1995). Both vaccinated groups developed submandibular abscesses but were not as clinically ill (i.e. did not develop fever, anorexia, malaise) as control 
horses following challenge. Further, horses vaccinated intraperitoneally developed IgG and $\operatorname{IgA}$ systemic and mucosal responses, but the horses vaccinated orally did not (Wallace et al. 1995). The oral route of administration is appealing for several practical reasons, even though it may not provide consistently superior immune activation and protection. In support of the utility to this route, it is plausible to suggest that the lack of systemic immune activation reported by Wallace, et al (1995) may reflect inactivated vaccine preparation rather than the oral route of administration.

In this investigation, no adverse effects to vaccination were found in any horses, consistent with other studies (Walker and Timoney. 2002; Fort Dodge Animal Health licensing report TIA number: 22740. 1997). There has been work on the live-attenuated strain to remove the hasA and has $B$ genes making the microorganism acapsular and incapable of reversion to an encapsulated and more virulent form (Waller and Jolley. 2007; Walker and Timoney. 2002). In a study to assess the safety of the vaccine used in our study, it was determined that the vaccine was safe and efficacious in adult horses with low antibody titers but may cause clinical disease in young, naïve ponies (Borst et al. 2011). Another study evaluated adverse behavioral responses to intranasal vaccine administration; while horses did not show any adverse responses, a few ponies did show substantial adverse reactions through avoidance behavior (Grogan and McDonnell. 2005).

On a separate note, we highlight that a novel microsphere assay was adopted here to measure immunologic response to $S$. equi vaccination. Potential advantages of the microsphere assay over the standard ELISA include smaller volumes of both protein and sample that are needed to perform the assay, as well as the potential to multiplex the assay to measure multiple analytes in the same sample (Baker et al. 2012). Thus this microsphere assay could also be modified for the quantitation of individual immunoglobulins (in $\mathrm{ng} / \mathrm{ml}$ ) in the sample, versus serum titers, which 
may be useful for determining immunologic response to vaccination or immunologic status against S. equi with further development.

In conclusion, we identified responses in serum IgG SeM titer elicited by both intranasal and oral vaccination for S. equi using the USDA-approved, live-attenuated vaccine (Pinnacle IN®, Zoetis, Florham Park, New Jersey). However, the magnitude of the response was considerably greater following the intranasal route of vaccination. It is unknown whether the levels of serum IgG identified in orally vaccinated horses confer protection against $S$. equi. Further work is warranted to definitively determine the potential utility of oral vaccination in horses. Until that time, manufacturer guidelines for the USDA-approved, live-attenuated S. equi vaccine (Pinnacle $\mathrm{IN}{ }^{\circledR}$, Zoetis, Florham Park, New Jersey) should be followed to ensure a maximal immune response. 


\section{Chapter 6 - Future work}

In this study, results using only MFI were analyzed. Future work on this project would include optimizing an equine IgA standard curve to obtain SeM-specific IgA concentrations. During this project, microspheres were coated with a monoclonal mouse anti-horse IgA (AbD Serotec, Kidlington, United Kingdom) as described in Chapter 3: Protein coupling to magnetic microspheres at a concentration of $5 \mu \mathrm{g} / 1 \times 10^{6}$ microspheres. A known horse reference serum (Bethyl Laboratorie, Inc, Montgomery, Texas) with a $1.5 \mathrm{mg} / \mathrm{ml}$ concentration of total IgA was diluted 1:3 to make standards of $0 \mathrm{ng} / \mathrm{ml}, 2.06 \mathrm{ng} / \mathrm{ml}, 6.17 \mathrm{ng} / \mathrm{ml}, 18.52 \mathrm{ng} / \mathrm{ml}, 55.56 \mathrm{ng} / \mathrm{ml}$, $166.67 \mathrm{ng} / \mathrm{ml}, 500 \mathrm{ng} / \mathrm{ml}$, and $1500 \mathrm{ng} / \mathrm{ml}$. These microspheres were incubated with the secondary antibody, goat anti-horse IgA (Bethyl Laboratories Inc, Montgomery, Texas), at a concentration of $4 \mu \mathrm{g} / \mathrm{ml}$ and detection antibody, PE-conjugated donkey anti-goat IgG (Thermo Fisher Scientific Inc., Rockford, Illinois), at a concentration of $4 \mu \mathrm{g} / \mathrm{ml}$ as described in Chapter 3: Quantitation (in MFI) of SeM protein-specific IgA. The standard curve samples were analyzed by the Luminex Magpix ${ }^{\circledR}$ (LuminexCorp., Austin, Texas), and the data was analyzed by the Milliplex ${ }^{\circledR}$ analyst software (EMD Millipore, Billerica, Massachusetts) to generate a standard curve (Table 3 and Figure 14). 
Table 3: Data from serum with known IgA concentration (ng/ml) used to generate a standard curve using Milliplex ${ }^{\circledR}$ analyst software (EMD Millipore, Billerica, Massachusetts).

\begin{tabular}{|c|c|c|c|c|c|c|c|}
\hline Location & $\begin{array}{c}\text { Expected } \\
\text { ng/ml(i) }\end{array}$ & $\operatorname{MFI}(\mathrm{i})$ & $\mathrm{ng} / \mathrm{ml}(\mathrm{i})$ & MFI & $\mathrm{ng} / \mathrm{ml}$ & $\mathrm{CV}$ & Recovery \\
\hline $1 \mathrm{~A} 1$ & 0 & 135 & & 89 & & $63.43 \%$ & \\
\hline 1B1 & & 155 & & & & & \\
\hline 1A11 & & 34 & & & & & \\
\hline $1 \mathrm{~B} 11$ & & 32 & & & & & \\
\hline $1 \mathrm{C} 1$ & 2.06 & 185 & 9.08 & 161.25 & 0.13 & $14.73 \%$ & $6.14 \%$ \\
\hline $1 \mathrm{D1}$ & & 137.5 & 1 & & & & \\
\hline 1E1 & 6.17 & 182 & 8.19 & 181 & 7.88 & $0.55 \%$ & $127.76 \%$ \\
\hline 1F1 & & 180 & 7.58 & & & & \\
\hline $1 \mathrm{G} 1$ & 18.52 & 217 & 17.43 & 220 & 18.14 & $1.36 \%$ & $97.93 \%$ \\
\hline $1 \mathrm{H} 1$ & & 223 & 18.84 & & & & \\
\hline $1 \mathrm{~A} 2$ & 55.56 & 438 & 57.81 & 420.5 & 55.05 & $4.16 \%$ & $99.09 \%$ \\
\hline $1 \mathrm{~B} 2$ & & 403 & 52.26 & & & & \\
\hline $1 \mathrm{C} 2$ & 166.67 & 1160 & 176.44 & 1129 & 170.06 & $2.72 \%$ & $102.03 \%$ \\
\hline $1 \mathrm{D} 2$ & & 1098 & 163.89 & & & & \\
\hline $1 \mathrm{E} 2$ & 500 & 1820 & 467.25 & 1804 & 450.58 & $0.91 \%$ & $90.12 \%$ \\
\hline $1 \mathrm{~F} 2$ & & 1787 & 435.1 & & & & \\
\hline $1 \mathrm{G} 2$ & 1500 & 2140 & 4963 & 2122 & 2494 & $0.85 \%$ & $166.27 \%$ \\
\hline $1 \mathrm{H} 2$ & & 2104 & 1797 & & & & \\
\hline
\end{tabular}


Figure 14: Standard curve generated using Milliplex® analyst software (EMD Millipore, Billerica, Massachusetts)

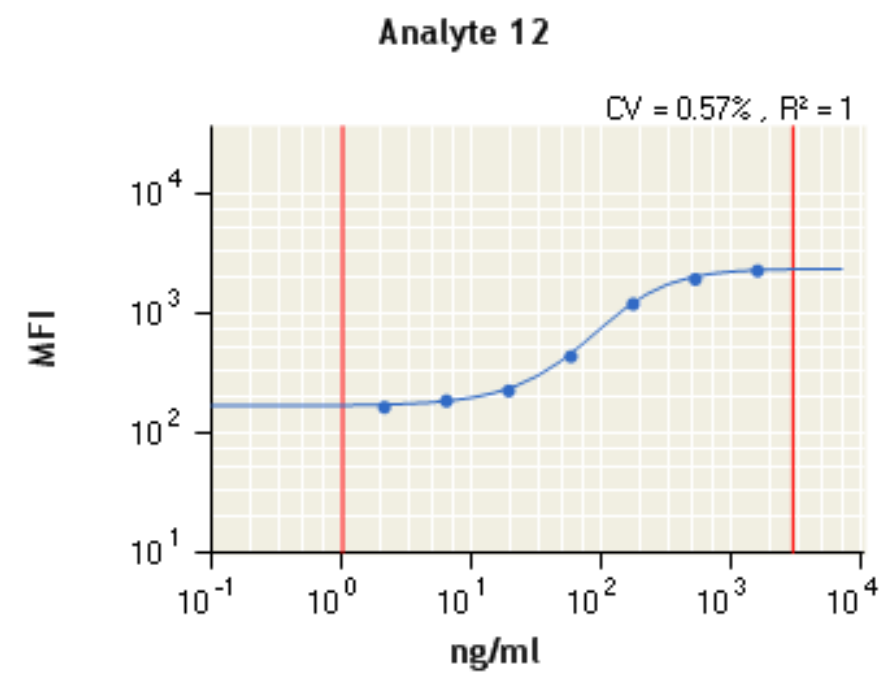

Dilutions of serum or nasal secretions can then be incubated with SeM protein coated microspheres, analyzed with the IgA standard curve samples using the Luminex Magpix ${ }^{\circledR}$ (LuminexCorp., Austin, Texas), and data in MFI compared to the standard curve to determine the SeM-specific IgA concentrations using Milliplex ${ }^{\circledR}$ analyst software (EMD Millipore, Billerica, Massachusetts).

The same can be performed using an equine IgG standard curve to obtain SeM-specific IgG concentrations. Microspheres can be coated with a purified anti-human IgG (Biolegend, San Diego, California) as described in Chapter 3: Protein coupling to magnetic microspheres at a concentration of $5 \mu \mathrm{g} / 1 \times 10^{6}$ microspheres. A known horse reference serum (Bethyl Laboratorie, Inc, Montgomery, Texas) with a $14.6 \mathrm{mg} / \mathrm{ml}$ concentration of total IgG can be diluted 1:2 to make standards of $0 \mathrm{ng} / \mathrm{ml}, 1.56 \mathrm{ng} / \mathrm{ml}, 3.12 \mathrm{ng} / \mathrm{ml}, 6.25 \mathrm{ng} / \mathrm{ml}, 12.5 \mathrm{ng} / \mathrm{ml}, 25 \mathrm{ng} / \mathrm{ml}, 50 \mathrm{ng} / \mathrm{ml}$, and $100 \mathrm{ng} / \mathrm{ml}$ as described in Chapter 2: Development of standard curves for quantitative measurements. These microspheres can be incubated with the secondary antibody, biotin goat 
anti-horse IgG (Jackson ImmunoResearch Laboratories Inc, West Grove, Pennsylvania), at a concentration of $4 \mu \mathrm{g} / \mathrm{ml}$ and detection antibody, PE-conjugated donkey anti-goat IgG (Thermo Fisher Scientific Inc., Rockford, Illinois), at a concentration of $4 \mu \mathrm{g} / \mathrm{ml}$ as described in Chapter 3: Quantitation (in MFI) of SeM protein-specific IgA. The standard curve samples can be analyzed by the Luminex Magpix ${ }^{\circledR}$ (LuminexCorp., Austin, Texas), and the data analyzed by the Milliplex ${ }^{\circledR}$ analyst software (EMD Millipore, Billerica, Massachusetts) to generate a standard curve (Table 2 and Figure 1).

In this study, a commercially-available SeM-specific IgG titer was performed to determine serum SeM-specific IgG. In the future, serum SeM-specific IgG concentrations can be correlated to SeM-specific IgG titers to determine level of protection and need for vaccination. 


\section{References}

Ainsworth DM, Cheetham J. (2010) Disorders of the Respiratory System. In: Equine Internal Medicine, $3^{\text {rd }}$ edn., Ed: Reed SM, Bayly WM, Sellon DC, Elsevier, St. Louis, Missouri. pp 306-311.

Sweeney CR, Timoney JF, Newton J, Hines MT. (2005) Streptococcus equi infections in horses: Guidelines for treatment, control, and prevention of strangles. J Vet Intern Med 19, 123134.

Timoney JF, Kumar P. (2008) Early pathogenesis of equine Streptococcus equi infection (strangles). Equine Vet J 40, 637-642.

Timoney JF. (2004) The pathogenic equine streptococci. Vet Res 53, 397-409.

Walker JA, Timoney JF. (2002) Construction of a stable non-mucoid deletion mutant of the Streptococcus equi Pinnacle vaccine strain. Vet Microbiol 89, 311-321.

Borst LB, Patterson SK, Lanka S, Barger AM, Fredrickson RL, Maddox CW. (2011) Evaluation of commercially available modified-live Streptococcus equi subsp equi vaccine in ponies. Am J Vet Res 72, 1130-1138.

Breiman RF, Silverblatt FJ. (1986) Systemic Streptococcu equi infection in a horse handler - A case of human strangles. West J Med 145, 385-386.

Duffee LR, Stefanovski D, Boston RC, Boyle AG. (2015) Predictor variable for and complications associated with Streptococcus equi subsp equi infection in horses. J Am Vet Med Assoc 247; 1161-1168.

Newton JR, Wood JL, Dunn KA, et al. (1997) Naturally occurring persistent and asymptomatic infection of the guttural pouches of horses with Streptococcus equi. Vet Rec 140; 84-90.

Waller A, Flock M, Smith K, Robinson C, Mitchell Z, Karlstrom A, Lannergard J, Bergman R, Guss B, Flock J-I. (2007) Vaccination of horses against strangles using recombinant antigens from Streptococcus equi. Vaccine 25; 3629-3635.

Sweeney CR, Whitlock RH, Meirs DA, et al. (1987) Complications associated with Streptococcus equi subspecies equi infection on a horse farm. J Am Vet Med Assoc 19; 1446-1448.

Whelchel DD, Chaffin MK. (2009) Sequelae and complications of Streptococcus equi subsp equi infections in the horse. Equine Vet Educ 21; 135-141.

Harrington DJ, Sutcliffe IC, Chanter N. (2002) The molecular basis of Streptococcus equi infection and disease. Microbes and Infection 4; 501-510. 
Timoney JF, Suther P, Velineni S, Artiushin SC. (2014) The antiphagocytic activity of SeM of Streptococcus equi requires capsule. J Equine Sci 25; 53-56.

Galan JE, Timoney JF. (1985) The immune response of the horse to an avirulent strain of Streptococcus equi. In: Recent Advances in Streptococci, Streptococcal Diseases, Ed: Kimura Y, Kotami S, Shiokawa Y, Reedbooks, Bracknell, UK. pp 294-295.

Merant C, Sheoran A, Timoney JF. (2011) Association of Streptococcus equi with equine monocytes. Veterinary Immunology and Immunopathology 143; 83-86.

Nara PL, Krakowka S, Powers TE, Garg RC. (1983) Experimental Streptococcus equi infection in the horse: correlation with in vivo and in vitro immune responses. American Journal of Veterinary Research 44; 529-534.

Sheoran AS, Sponseller BT, Holmes MA, Timoney JF. (1997) Serum and mucosal antibody isotype responses to M-like protein (SeM) of Streptococcus equi in convalescent and vaccinated horses. Vet Immunol Immunopathol 59, 239-251.

Sheoran AS, Timoney JF, Holmes MA, Karzenski SS, Crisman MV. (2000) Immunoglobulin isotypes in sera and nasal mucosal secretions and their neonatal transfer and distribution in horses. American Journal of Veterinary Research 61; 1099-1105.

Timoney JF, Eggers DE. (1985) Serum bactericidal responses to Streptococcus equi of horses following infection or vaccination. Equine Vet J 17; 306-310.

Lindahl S, Baverud V, Egenvall A, Aspan A, Pringle J. (2013) Comparison of sampling sites and laboratory diagnostic tests for $S$. equi subsp equi in horses from confirmed strangles outbreaks. Journal of Veterinary Internal Medicine 27; 542-547.

Boyle AG, Sweeney CR, Kristula M, Boston R, Smith G. (2009) Factors associated with likelihood of horses having a high serum Streptococcus equi SeM-specific antibody titer. Journal of the American Veterinary Medical Association 235; 973-977.

Robinson C, Steward KF, Potts N, Barker C, Hammond T, Pierce K, Gunnarsson E, Svansson V, Slater J, Newton JR, Waller AS. (2013) Combining two serological assays optimizes sensitivity and specificity for the identification of Streptococcus equi subsp equi exposure. The Veterinary Journal 197; 188-191.

Cursons R, Patty O, Steward KR, Waller AS. (2015) Strangles in horses can be caused by vaccination with Pinnacle IN. Vaccine 33; 3440=3443.

Mallicote M. (2015) Update on Streptococcus equi subsp equi infection. Veterinary Clinics of North America Equine Practice 31; 27-41. 
Hoffman AM, Staempfli JR, Prescott JF. (1991) Field evaluation of a commercial M-protein vaccine against Streptococcus equi infection in foals. American Journal of Veterinary Research 52; 589-592.

Kelly C, Bugg M, Robinson C, Mitchell Z, Davis-Poynter N, Newton JR, Jolley KA, Maiden MC, Waller AS. (2006) Sequence variation of the SeM gene of Streptococcus equi allows discrimination of the source of strangles outbreaks. Journal of Clinical Microbiology 44; 480-486.

Jacobs AAC, Goovaerts D, Nuijten PJM, Theelen RPH, Hartford OM, Foster TJ. (2000) Investigations towards an efficacious and safe strangles vaccine: submucosal vaccination with a live attenuated Streptococcus equi. The Veterinary Journal 147; 563-567.

Kemp-Symonds J, Kemble T, Waller A. (2007) Modified live Streptococcus equi ('strangles') vaccination followed by clinically adverse reactions associated with bacterial replication. Equine Veterinary Journal 39; 284-286.

Velineni S, DeNegri R, Artiushin SC, Timoney JF. (2015) Comparison of specificities of serum antibody responses of horses to clinical infections caused by Streptococcus equi or zooepidemicus. Veterinary Microbiology 180; 253-259.

Hobo S, Niwa H, Anzai T, Jones JH. (2010) Changes in serum antibody levels after vaccination for strangles and after intranasal challenge with Streptococcus equi subsp. equi in horses. J Equine Science 3; 33-37.

Flock M, Jacobsson K, Frykberg L, Hirst TR, Franklin A, Guss B, Flock J-I. (2004) Recombinant Streptococcus equi proteins protect mice in challenge experiments and induce immune response in horses. Infection and Immunity 72; 3228-3236.

Flock M, Karstrom A, Lannergard J, Guss B, Flock J-I. (2006) Protective effect of vaccination with recombinant proteins from Streptococcus equi subspecies equi in a strangles model in the mouse. Vaccine 24; 4144-4151.

Timoney JF, Qin A, Muthupalani S, Artiushin. (2007) Vaccine potential of novel surface exposed and secreted proteins of Streptococcus equi. Vaccine 25; 5583-5590.

Robinson C, Heather Z, Slater J, Potts N, Steward KF, Maskell DJ, Fontaine MC, Lee J-J, Smith K, Waller AS. (2015) Vaccination with a live multi-gene deletion strain protects horses against virulent challenge with Streptococcus equi. Vaccine 33; 1060-1067.

Sheoran AS, Artiushin S, Timoney JF. (2002) Nasal mucosal immunogenicity for the horse of a SeM peptide of Streptococcus equi genetically coupled to cholera toxin. Vaccine 20; 1653-1659.

Nally JE, Artiushin S, Sheoran AS, Burns PJ, Simon B, Gilley RM, Sullivan GS, Timoney JF. (2001) Induction of mucosal and systemic antibody specific for SeMF3 of Streptococcus 
equi by intranasal vaccination using a sucrose acetate isobutyrate based delivery system. Vaccine 19; 492-497.

Florindo JF, Pandit S, Lacerda L, Goncalves LMD, Alpar HO, Almeida AJ. (2009) The enhancement of the immune response against $S$. equi antigens through the intranasal administration of poly- $\varepsilon$-caprolactone-based nanoparticles. Biomaterials 30; 879-891.

Figueiredo L, Cadete A, Goncalves LMD, Corvo ML, Almeida AJ. (2012) Intranasal immunization of mice against Streptococcus equi using positively charged nanoparticulate carrier systems. Vaccine 30; 6551-6558.

Grogan EH, McDonnell SM. (2005) Behavioral responses to two intranasal vaccine applicators in horses and ponies. Journal of the American Veterinary Medical Association 226, 16891693.

Jakobsen J, Jonsdottir I. (2003) Mucosal vaccination against encapsulated respiratory bacterianew potential for conjugate vaccines? Scandinavian Journal of Immunology 58; 119128.

Kumar P, Timoney JF, Sheoran AS. (2001) M cells and associated lymphoid tissue of the equine nasopharyngeal tonsil. Equine Veterinary Journal 33; 224-230.

Holmgren J, Czerkinsky C. (2005) Mucosal immunity and vaccines. Nat Med 11, S45-S53.

Wilkie BN. (1982) Respiratory tract immune response to microbial pathogens. Journal of the American Veterinary Medical Association 181; 1074-1079.

Wallace FJ, Emery JD, Cripps AW, Husband AJ. (1995) An assessment of mucosal immunization in protection against Streptococcus equi ('Strangles') infections in horses. Veterinary Immunology and Immunopathology 48, 139-154.

Behrend MR, Karima HH, Nigmatulina KR, Eckhoff P. (2014) A quantitative survey of the literature on poliovirus infection and immunity. International Journal of Infectious Diseases 18; 4-13.

Dabral N, Moreno-Lafont M, Sriranganathan N, Vemulapalli R. (2014) Oral immunization of mice with gamma-irradiated Brucella neotomae induces protection against intraperitoneal and intranasal challenge with virulent B. abortus 2308. PLOS ONE 9;e107180.

Pasternak JA, Ng SH, Wilson HL. (2014) A single, low dose oral antigen exposure in newborn piglets primes mucosal immunity if administered with $\mathrm{CpG}$ oligodeoxynucleotides and polyphosphazene adjuvants. Veterinary Immunology and Immunopathology 161; 211-221.

Angeloni S, Cordes R, Dunbar S, Garcia C, Gibson G, Martin C, Stone V. (2016) xMAP Cookbook. Luminexcorp.com 
Christopher-Hennings J, Araujo KPC, Souza CJH, Fang Y, Lawson S, Nelson EA, Clement T, Dunn M, Lunney JK. (2013) Opportunities for bead-based multiplex assay in veterinary diagnostic laboratories. Journal of Veterinary Diagnostic Investigation 25; 671-691.

Baker JN, Murphy R, Lopez E, Garcia C. (2012) Conversion of a capture ELISA to a Luminex xMAP assay using a multiplex antibody screening method. $J$ Vis Exp 65, 1-8.

Bates DM, Watts DG. (1988) Nonlinear Regression Analysis and its Applications. New York: Wiley.

Wagner B, Freer H. (2009) Development of a bead-based multiplex assay for simultaneous quantification of cytokines in horses. Vet Immuno Immunopathol 127; 242-248.

Hall SA, Stucke D, Morrone B, Lebelt D, Zanella AJ. (2015) Simultaneous detection and quantification of six equine cytokines in plasma using a fluorescent microsphere assay (FMIA). MethodsX 2; 241-248.

Balasuriya UBR, et al. (2006) Detection of antibodies to West Nile virus in equine sera using microsphere immunoassay. J Vet Diagn Invest 18; 392-395.

Beck C, et al. (2015) A high-performance multiplex immunoassay for serodiagnosis of flavivirusassociated neurological diseases in horses. BioMed Research International. http://dx.doi.org/10.1155/2015/678084.

Go YY, et al. (2008) Development of a fluorescen-microsphere immunoassay for detection of antibodies specific to equine arteritis virus and comparison with the virus neutralization test. Clinical and Vaccine Immunology 15; 76-87.

Sanchez-Matamoros A, Beck C, Kukielka D, Lecollinet S, Blaise-Boisseau S, Garnier A, Rueda P, Zientara S, Sanchez-Vizcaino JM. (2015) Transboundary and Emerging Diseases. Doi:10.1111/tbed.12340

Wagner B, Freer H, Rollins A, Erb HN, Zhao L, Grohn Y. (2011) Vet Immunol Immunopathol 144; 374-381.

McNabb L, Barr J, Crameri G, Juzva S, Riddell S, Colling A, Boyd V, Broder C, Wang LF, Lunt R. (2014) Henipavirus microsphere immune-assays for detection of antibodies against Hendra virus. Journal of Virological Methods 200; 22-28.

Harms D, Mapes S, Akana N, Coatti Rocha D, Pusterla N. (2014) Detection of modified-live equine intranasal vaccine pathogens in adults horses using quantitative PCR. The Veterinary Record. Doi:10.1136/vr.102592

Nelson KM, Schram BR, McGregor MW, Sheoran AS, Olsen CW, Lunn DP. (1998) Local and systemic isotype-specific antibody responses to equine influenza virus infection versus conventional vaccination. Vaccine 16, 1306-1313. 
Tizard IR. (2013) Veterinary Immunology. Elsevier, St. Louis, Missouri. pp 165-175.

McKercher DG, Kaneko JJ, Mills RJ, Wada EM. (1973) Simple method for obtaining undiluted nasal secretions. American Journal of Veterinary Research 6; 837-838.

Waller AS, Jolley KA. (2007) Getting a grip on strangles: Recent progress towards improved diagnostics and vaccines. The Veterinary Journal 173, 492-501. 